

\section{Sumário}

\section{Crônicas}

CRôNICAS DA ATUALIDADE do DiREITO INTERNACIONAL ........................................................ 2

Nitish Monebhurrun (org.)

Towards a european regulation of the importation of conflict minerals?..... 2

Nitish Monebhurrun

Keeping up with the terrorists: the EU's proposed Passenger Name Records (PNR) Directive \& european security

Eshan Dauhoo

A histórica reaproximação de Cuba e EUA

Erika Braga

A contextualização da atual reivindicação da Grécia para receber indenizações por atos da Alemanha durante a Segunda Guerra Mundial . .10

Natália da Silva Gonçalves

José Eduardo Paiva Miranda de Siqueira

Crônicas da jurisprudência do Direito Internacional (CIJ/ITLOS): Decisões da Corte Internacional de Justiça e do Tribunal Internacional Sobre o Direito do Mar .14

Nitish Monebhurrun (Org.)

Corte Internacional de Justiça

Estudo da decisão da Corte Internacional de Justiça no caso Croácia v. Servia (03/02/2015) .14

Liziane Paixão Silva Oliveira e Maria Edelvacy Marinho

Questões relacionadas com a apreensão e detenção de certos documentos e dados: (Timor Leste c. Austrália) - O reconhecimento do retorno de uma relação amigável entre Timor-Leste e Austrália e a nova decisão da CIJ, 6 de maio de 2015 . 20

Gleisse Ribeiro Alves

Tribunal Internacional sobre Direito do Mar

Caso da delimitação da fronteira marítima entre o Gana e a Costa do Marfim no Oceano Atlântico: medidas cautelares $(25 / 04 / 2015)$

Nitish Monebhurrun

Comentário à Opinião Consultiva 21 do Tribunal Internacional para o Direito Do Mar [02/04/2015] (Responsabilidade do Estado de Bandeira pela pesca ilícita, não declarada ou não regulamentada) ...............25

Carina Costa de Oliveira 
CRÔNICAS DO DIREITO INTERNACIONAL DOS INVESTIMENTOS

Nitish Monebhurrun (Org.)

A inclusão da responsabilidade social das empresas nos novos Acordos de Cooperação e de Facilitação dos Investimentos do Brasil: uma revolução 33

Nitish Monebhurrun

\section{O Direito do Mar Perante as JuRisdições INTERnacionais}

CoAstal States' Rights IN THE MARITIME AREAS UNDER UNCLOS .40 Tullio Treves

TACKling illegal, unregulated And unReported Fishing: THE ITLOS Advisory OpINION on Flag State Responsibility for IUU fishing AND THE PRINCiple of DUE DiligenCE ...50 Victor Alencar Mayer Feitosa Ventura

REFLEXões PROVENIENTES do DisSENSO: UMA ANÁLISE CRÍtica A RESPEITO do CASO Austrália versus Japão Perante a Corte InTERnacional de JustiçA .......................................68 Luciana Ferna ndes Coelho

Os TRATADOS INTERNACIONAIS DE DIREITO DO MAR E SEUS EFEITOS SOBRE TERCEIROS ESTADOS ..... 86 Tiago V. Zanella

\section{InStRumentos JURÍdicos PARA A GeStÃo do MAR}

OS LIMITES DOS TERMOS BEM PÚBLICO MUNDIAL, PATRIMÔNIO COMUM DA HUMANIDADE E BENS COMUNS PARA DELIMITAR AS OBRIGAÇÕES DE PRESERVAÇÃO DOS RECURSOS MARINHOS 109 Carina Costa de Oliveira e Sandrine Maljean-Dubois

Os limites do PLANEJAMENTO DA OCUPAÇÃo SUSTENTÁVEL DA ZONA COSTEIRA BRASILEIRA ... 126 Carina Costa de Oliveira e Luciana Coelho

CORRENDO PARA O MAR NO ANTROPOCENO: A COMPLEXIDADE DA GOVERNANÇA DOS OCEANOS E A ESTRATÉGIA BRASILEIRA DE GESTÃO DOS RECURSOS MARINHOS 
A comissão de limites da Plataforma continental (CLPC) E Os DESAFios Na delineaÇÃo DAS PLATAFORMAS CONTINENTAIS ESTENDIDAS................................................... 170

Alexandre Pereira da Silva

\section{A PROTEÇÃo DO MEIO AMBIENTE MARINHO}

O gRANDE JOGo do ÁrTiCo: REFLEXões COM BASE NA PERSPECTIVA DE EXPLORAÇão ECONÔMICA

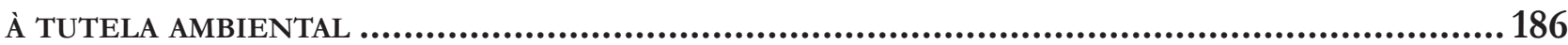

Fernando Rei e Valeria Cristina Farias

Instrumentos Públicos e Privados para a reparação do dano ambiental causado por DERRAMAMENTO DE ÓLEO NO MAR SEM ORIGEM DEFINIDA: AS MANCHAS ÓRFÃS

Renata Brockelt Giacomitti e Katya R. Isaguirre-Torres

O DIREITO INTERNACIONAL PRIVADO E A RESPONSABILIDADE CIVIL EXTRACONTRATUAL POR DANOS AMBIENTAIS CAUSADOS POR TRANSPORTES MARÍTIMOS À LUZ DO DIREITO BRASILEIRO ....... 217 Inez Lopes

A NECESSIDADE DE REPENSAR OS MECANISMOS DE RESPONSABILIDADE AMBIENTAL EM CASO DE riscos de VAZamento de PETRóleo Na Zona Econômica Exclusiva do BrasiL

Marcelo D. Varella

\section{Problemáticas do Direito Marítimo}

A FisCALIZAÇão SANitÁRIA DAS EMBARCAÇÕES EM ÁGUAS JURISDICIONAIS BRASILEIRAS: NOTAS aCERCA da (IN)efetividade da Súmula 50 da AGU

Joedson de Souza Delgado e Ana Paula Henriques da Silva

A IMO E A REPRESSÃo AO ROUBO ARMADO CONTRA NAVIOS: DA RETÓRICA INTERNACIONAL À COOPERAÇÃO REGIONAL

André Panno Beirão e Charles Pacheco Piñon

\section{O Direito do Mar diante da Pirataria}

O DIREITO INTERNACIONAL EM FACE DA PIRATARIA EM ALTO-MAR: UMA PERSPECTIVA CRÍTICA.289 Maiquel Ângelo Dezordi Wermuth e Rafaela Correa 
Pirataria marítima: A EXPERIÊnCIA Somália

Eduardo Augusto S. da C. Schneider

\section{Temas Gerais}

DRAWING THE LINE: ADDRESSING ALLEGATIONS OF UNCLEAN HANDS IN INVESTMENT ARBITRATION*

Mariano de Alba

Para Que Serve a história do Direito internacional?

George Rodrigo Bandeira Galindo

As interferências entre a Política Externa e de Segurança Comum Europeia (Pesc) e O DiREITO DAS NaÇões UNIDAS

Leonardo de Camargo Subtil

Introdução Às regras de aplicaÇão da Convenção da ONU Sobre Contratos de ComPRA E VENDA INTERNACIONAL DE MERCADORIAS E O DIREITO INTERNACIONAL PRIVADO BRASI-

LEIRO 380

Paul Hugo Weberbauer e Eugênia Cristina Nilsen Ribeiro Barza

A REgulaÇÃo das EMPRESAS TRANSNACIONAIS ENTRE AS ORDENS JURÍDICAS ESTATAIS E NÃO ESTATAIS.

Mateus de Oliveira Fornasier e Luciano Vaz Ferreira

OUtLAWING HATE SPEECH IN DEMOCRATIC STATES: THE CASE AGAINST THE INHERENT LimitAtions doctrine concerning Article 10 (1) of the European Convention on Human

Rights 416

Stefan Kirchner 


\title{
Correndo para o mar no antropoceno: a complexidade da governança dos oceanos e a estratégia brasileira de gestão dos recursos marinhos*
}

\author{
Race to the sea in the anthropocene: the \\ complexity of oceans governance and the \\ brazilian strategy for the marine resources \\ management
}

\author{
Ana Flávia Barros-Platiau** \\ Jorge Gomes do Cravo Barros*** \\ Pierre Mazzega**** \\ Liziane Paixão Silva Oliveira*****
}

* Recebido em 10/04/2015

Aprovado em 04/06/2015

** Professora em Relações Internacionais da Universidade de Brasília (UnB). Atualmente em pós-doutorado no CERIC (Université Aix Marseille) pelo projeto "A Estratégia Brasileira na Gestão de Recursos Vivos e Não-vivos do Mar ", CAPES/Brasil. E-mail: anaflavia@teaser.fr

*** Geólogo. Ex-Professor da Universidade de Brasília e ex-Assessor em Geologia da 4a. CCR, Ministério Público Federal. E-mail: jorgecravobarros@gmail.com

**** Diretor de Pesquisa no CNRS, UMR5563 Géosciences Environnement Toulouse (Universidade de Toulouse, França). Email:pmazzega@gmail.com

***** Professora de Direito Ambiental na Universidade Tiradentes, Coordenadora do Programa de Pós-Graduação em Direito da Universidade Tiradentes/Mestrado em Direitos Humanos, atualmente em Pós-doutorado no CERIC (Université Aix-Marseille). E-mail: lizianepaixao@gmail.com

\section{Resumo}

Partindo da premissa que estamos na época geológica do Antropoceno, este artigo tem por objetivo sugerir orientações para a estratégia brasileira de gestão e proteção de recursos marinhos, considerando a evolução do direito do mar e o contexto multilateral atual desde 1973, quando iniciou-se a III Conferência sobre o Direito do Mar sob a égide da ONU. Primeiramente são descritas transformações profundas no contexto internacional, o que justifica o interesse do artigo e a adoção do conceito de "ordem global ambiental". Tal ordem é definida pela complexidade crescente da governança dos oceanos e pela corrida para o mar de países emergentes, dentre os quais o Brasil. Em contraposição, é analisada a lenta evolução do direito do mar, conduzindo à imprescindibilidade de maior circulação de normas entre diversos espaços convencionais. Finalmente, são abordados os principais traços da estratégia brasileira relativa aos recursos do mar, com o fito de esclarecer que a primeira sugestão é de uma abordagem mais integrada da questão marítima no arcabouço político-legal, principalmente para a regulação do uso dos recursos e da reparação de eventuais danos. A segunda sugestão concerne às parcerias estratégicas, em virtude do pleito brasileiro de extensãoda Plataforma Continental. Por fim, participar mais ativamente das reuniões multilaterais é essencial para o Brasil, que constitui um global player ambiental, mas não é uma potência marítima. A originalidade do artigo reside na análise, empregando conceitos de relações internacionais e direito internacional, propondo ideias para o Brasil ganhar capacidade de interlocução à altura de suas ambições marítimas.

Palavras-chave: Amazonia Azul. Antropoceno. Brasil. Circulação de normas. Complexo de regimes. Governança dos oceanos. 
Abstract

Taking into account the fact that we are in the Anthropocene epoch, this article aims at suggesting ways the Brazilian strategy for the protection and management of marine resources could be improved. First, the deep changes in the international context are discussed, leading to the concept of "global environmental order". The rising complexity of oceans governance and the race to the sea, including new emerging competitors, such as China and Brazil, are the key features of the global order. While those changes were fast, the evolution of the international environmental law was so slow it is now urgent to improve the circulation of norms related to the regulation of sustainable use of resources and damage reparation, notably on the high seas. In this context, the Brazilian strategy is encouraged to admit that an integrated institutional approach is necessary to forge the national interests more clearly. Had Brazil done so, it would have a better international image. The second suggestion concerns the improvement of its strategic partnerships, since Brazil is pleading the extension of the Continental Platform. Finally, since Brazil is an environmental global player, but not one related to sea issues, it is mandatory Brazil participates more actively in multilateral meetings. The main interest of this article is to analyse international relations and international law concepts to suggest how Brazil could have a voice as strong as its maritime ambitions.

Keywords: Blue Amazon. Anthropocene. Brazil. Norms circulation. Ocean governance. Regimes complex.

\section{INTRODUÇÃO1}

Apesar do atual debate acalorado entre cientistas, tem se consolidado, nos últimos anos, o consenso relativo ao início da nova época geológica, chamada de Antropoceno. Ele corresponderia à época das negociações no âmbito da III Conferência das Nações Unidas sobre o Direito do Mar de 1973, que levou à assinatura da Convenção das Nações Unidas sobre Direito do Mar

1 Pesquisa financiada pela CAPES, projeto "A Estratégia Brasileira na Gestão de Recursos Vivos e Não-vivos do Mar» Edital n.43/ Ciências do Mar e Agence Nationale de Recherche (França), projeto CIRCULEX < ANR-12-GLOB-0001-03 CIRCULEX>, do CERIC , Université Aix Marseille
(UNCLOS) em $1982^{2}$. Passadas mais de quatro décadas de avatares ambientais e institucionais, nota-se que os primeiros evoluiram mais rapidamente do que os segundos ${ }^{3}$. Consequentemente, a governança dos oceanos tornou-se ainda mais complexa, revelando crescente e necessária circulação de normas regulatórias das atividades humanas. Nesse contexto, diversos países têm assumido interesse renovado pelos recursos marinhos em razão de dois fatores: a preocupação generalizada com a segurança energética e alimentar nacional, bem como o acelerado desenvolvimento tecnológico (principalmente de países emergentes). Sendo o Brasil ${ }^{4}$ um deles, cabe então analisar esse contexto internacional para orientar a estratégia brasileira, usando como pano de fundo as profundas mudanças estruturais que conduziram ao que se convém denominar "ordem ambiental global".

Nesse sentido, o principal objetivo do artigo consiste em discutir o contexto internacional contemporâneo, com base em uma abordagem político-jurídica, para informar os tomadores de decisão e o juristas brasileiros. O recorte temporal é de 1973 a 2014, ou seja, das negociações que levariam à assinatura da UNCLOS até 2014, ano que marca o fim da ordem ambiental internacional do século XX. O ano de 2015 marcará o final dos Objetivos de Desenvolvimento do Milênio (ODM) e o início dos Objetivos de Desenvolvimento Sustentável $(\mathrm{ODS})^{5}$, bem como a realização da Conferência das Partes à Convenção-Quadro das Nações Unidas

2 A Convenção das Nações Unidas sobre Direito do Mar entrou em vigor somente em novembro de 1994.

3 Outros artigos desta edição partem da mesma premissa. Ver Oliveira, Carina Costa de e Maljean-Dubois, Sandrine. Os limites dos termos bem público mundial, patrimônio comum da humanidade e bens comuns para delimitar as obrigações de preservação dos recursos marinhos. Também da Silva, Alexandre Pereira. A comissão de limites da plataforma continental (CLPC) e os desafios na delineação das plataformas continentais estendidas. Revista de Direito Internacional, vol.12, no.1. (nesta edição).

4 O Brasil é considerado um global player nas questões ambientais, ou seja, ator com influência para orientar os resultados de negociações multilaterais, por diversas razões. A principal é a sua capacidade de interlocução na maior parte da agenda ambiental, como temas afetos a florestas e diversidade biológica, porém as questões relativas ao mar são ainda exceção. Sobre florestas e clima, ver CARVALHO, Fernanda. The brazilian position on forests and climate change from 1997 to 2012: from veto to proposition. Revista Brasileira de Politica Internacional, Rio de Janeiro, v. 55, n. spe, p. 144-169, 2012.

5 UNITED NATIONS. Department of Economic and Social Affairs. Goal 14: conserve and sustainably use the oceans, seas and marine resources for sustainable development. Disponível em: <http://una-gp.org/clancyt/files/goals/goal14.pdf>. Acesso em: 23 mar. 2015. 
sobre Mudanças do Clima (UNFCCC) em Paris (COP 21), cuja ambição constitui a assinatura de tratado internacional cogente com vocação universal ${ }^{6}$. Apesar da importância indiscutível do regime climático sobre os oceanos e seus recursos, esse tema será tratado neste artigo de forma secundária. Da mesma forma, teria sido interessante estudar em profundidade o pleito brasileiro de extensão da Plataforma Continental para além das 200 milhas junto à Comissão de Limites da ONU, porém a Fundação Alexandre Gusmão (FUNAG) publicou no ano passado duas excelentes obras sobre o tema, com abordagem primordialmente político-legal, e disponíveis on-line. Assim, o presente artigo dialoga com textos recentes tanto da diplomacia brasileira quanto do direito internacional, sem perder de vista a produção científica nas ciências da vida, especialmente da revista Nature, e dados oficiais do sistema ONU e de outras instituições pertinentes?

\section{A CORRIDA PARA O MAR NO ANTROPOCENO}

$\mathrm{Na}$ história Ocidental, a verdadeira corrida para o mar geralmente começa com as grandes navegações e o cruzamento dos oceanos, levando inclusive à constatação que foi uma primeira versão da globalização ${ }^{8}$. Uma das principais motivações para a aventura marítima era a "descoberta" de novas terras e riquezas. Logo, a apropriação de recursos naturais ${ }^{9}$ foi objetivo central das civilizações ao longo dos séculos e um desafio de regulação para os atores institucionais que seriam criados com o passar do tempo.

6 CONFÉRENCE DES PARTIES DE LA CONVENTIONCADRE DES NATIONS UNIES SUR LES CHANGEMENTS CLIMATIQUES, 21., 2015, Paris. Procédure eletrônicos... Paris: UNFCC, 2015. Disponível em: < http://www.cop21.gouv.fr/fr>. Acesso em: 23 mar.2015.

7 Ver também da Silva, Alexandre Pereira. A comissão de limites da plataforma continental (CLPC) e os desafios na delineação das plataformas continentais estendidas. Revista de Direito Internacional, vol.12, no.1. (nesta edição).

8 GOIS, Ancelmo; BARROS-PLATIAU, Ana Flávia. Direito internacional e globalização face as questões de direitos humanos. In: RIBEIRO, M.; MAZZUOLI, Valério (Coord.). Direito internacional dos direitos humanos: estudos em homenagem à professora Flávia Piovesan. Curitiba: Juruá, 2004. p. 57-71.

9 No caso dos recursos marinhos, o texto aborda a proteção e gestão de recursos vivos e não vivos, também definidos como bióticos e abióticos, ou biológicos e minerais. Interessa particularmente a exploração de petróleo e nódulos metálicos, como também a pesca e a caça de espécies migratórias e os corais.
Desde o século XVI, países desenvolvidos ocidentais exploraram e colonizaram territórios que eram habitados por populações autoctonas, dividindo a arena internacional em duas metades asimétricas, inclusive para a construção do direito internacional público, e iniciando o que se conveniou denominar clivagem Norte/Sul, ou seja, países desenvolvidos versus países em desenvolvimento ${ }^{10}$. Entretanto, tal clivagem torna-se cada vez mais sutil com o fortalecimento acelerado de economias de países que não tinham tanta capacidade de interlocução no cenário político internacional no passado recente, entre eles, para citar apenas alguns, China, Índia e Brasi $1^{11}$. A escolha dos três justifica-se por duas razões principais. Primeiramente, nenhuma análise com dimensão internacional pode ignorar a irrupção da China como ator de primeira grandeza, mesmo que sua participação política em foruns multilaterais ainda não corresponda à sua potência econômica, marítima e climática ${ }^{12}$. Segundo, a China tem intensificado o seu esforço para integrar a ordem liberal ocidenta $1^{13}$ ao tornar-se membro das organizações intergovernamentais, principalmente a OMC, e também ao criar meios de articulação política com Brasil e Índia, principalmente no BRICS e BASIC, e em menor medida, em outras questões, como a climática ${ }^{14}$. Sendo China e Índia duas novas potências tecno-

10 Clivagem que persiste de modo geral na agenda ambiental e de desenvolvimento, como na Plataforma Intergovernamental de Biodiversidade e Serviços Ecossitêmicos (IPBES) INTERGOVERNMENTAL platform on biodiversity and ecosystem services. 2015. Disponível em: <http://www.ipbes.net/>. Acesso em: 23 mar. 2015. Ver também MORIN, Jean-Frédéric; ORSINI, Amandine. Essential concepts of global environmental governance. Abingdon: Routledge, 2014. Ver também DELEUIL, Thomas. Le statut des pays en voie de développement dans les Accords Multilatéraux Environnementaux. 2014. $\mathrm{f}$ Thèse $(\mathrm{PhD})$ - Centre d'Etudes et de Recherches Internationales et Communautaires (CERIC, CNRS UMR 7318), Faculté de Droit d'Aix en Provence, Université Paul Cézanne Aix-Marseille, Marseille 2014.

11 Estima-se que o interesse brasileiro pelos recursos marinhos intensificou-se nos anos 1960, com a descoberta de petróleo offshore. 12 Para o conceito de potência climática, ver VIOLA, Eduardo; FRANCHINI, Matías; RIBEIRO, Thaís. Sistema internacional de begemonia conservadora: democracia e governança global na era da crise climática. São Paulo: Annablume, 2013.

13 PRANTL, Jochen. Taming hegemony: informal institutions and the challenge to western liberal order. The Chinese Journal of International Politics, Oxford, v. 7, n. 4, p. 449-482, Winter, 2014.

14 Sobre BRICS e clima, ver GOLDEMBERG, José; VIOLA, Eduardo. BRICS e as mudanças climáticas. 2014. Disponível em: $<$ http://politicaexterna.com.br/2580/brics-e-mudancas-climaticas/>. Acesso em: 19 mar. 2015. Sobre a Cúpula do BRICS de Fortaleza em 2014, Ver BECARD, Danielly; BARROS-PLATIAU, Ana Flávia; OLIVEIRA, Carina. Brasil, a China e a VI Cúpula do BRICS. Contexto Internacional, v. 37, n. 1, 2015. No prelo. 
lógicas com alto potencial de crescimento nas próximas décadas, é natural que se preocupem com a apropriação de recursos marinhos. No caso chinês, o potencial de conflitos no mar da China revela-se extremamente importante na agenda nacional em razão de dois casos recentes, mas que fogem ao escopo deste estudo: o contencioso com o Vietnam que reflete a ambição chinesa para a região e o acidente nuclear de Fukushima no Japão, que contaminou o mar, ambos de 2014. Esses dois casos demonstram a fragilidade das instituições internacionais em aportar respostas concretas à $\mathrm{China}^{15}$ e serão objeto de reflexão em pesquisa futura.

Finalmente, seria arriscado defender o conceito de "nova corrida para o mar" em termos econômicos e ambientais como fez James Moltz ${ }^{16}$ em relação aos submarinos nucleares, posto que a corrida é contínua, e na maioria das vezes os Estados e empresas não revelam seus interesses, muito menos o escopo e objeto de suas atividades no alto-mar. Todavia, é possível afirmar que houve « ondas de interesse $»^{17}$ no passado recente, que o comportamento de um país influência os demais e que a irrupção dos países emergentes nas inovações tecnológicas pertinentes trouxe novo alento à corrida ora em curso, ou em vias de planejamento ${ }^{18}$. Em larga medida, as negociações multilaterais para regular a proteção e o acesso aos recursos marinhos são calcadas nessas ondas de interesse, como foi o caso da UNCLOS.

Concomitantemente às negociações multilaterais para estabelecer a $\mathrm{UNCLOS}^{19}$, um número crescente de

15 Sobre as obrigações positivas do Estado e as lacunas do direito internacional público e do sistema ONU, ver ALFAIA JR., José Roberto. Reclamar ou intervir? As obrigações positivas do estado em situações de desastre ambiental. 2014. f. Tese (Doutorado) - Instituto de Relações Internacionais, Universidade de Brasília, Brasília, 2014.

16 MOLTZ, James Clay. Submarine and autonomous vessel proliferation: implications for future strategic stability at sea. Disponível em: <http://calhoun.nps.edu/handle/10945/34355 em 2012>. Acesso em: 23 mar. 2015.

17 A criação da ZEE foi um caso. O interesse de certos paises pelos fundos marinhos fora de suas respectivas jurisdições, pelo Artico e a Antartida sao outros casos relevantes. Restam ainda os diferendos entre paises sobre a posse de ilhas, por exemplo, dos quais as Malvinas interessa diretamente ao Brasil.

18 Como destacado, a China é o maior investidor emergente e o caso mais interessante atualmente. Em menor medida, Rússia, Brasil, India, Chile, México, Tailândia, entre outros, são casos relevantes. Sobre a Antártica, ver SAMPAIO, Daniela. Antarctica and international cooperative practices. São Paulo: International Studies Association, March 2014. (working paper). Disponível em: <http:// www.academia.edu/10185759/Antarctica_and_International_Cooperative_Practices_working_paper>. Acesso em: 23 mar. 2015.

19 Ela entrou em vigor apenas em 1994. cientistas defende que iniciou-se uma nova época geológica, o Antropoceno ${ }^{20}$, estabelecida com base nos impactos das atividades humanas sobre o Planeta ${ }^{21}$. Contudo, ainda está sob discussão se o seu início poderia ser cientificamente comprovado, e, em caso positivo, se deveria ser marcado pelo momento dos aproximadamente 500 testes nucleares entre 1945 e $1963^{22}$, ou pelo uso desenfreado de recursos renováveis e não renováveis, sem esquecer a produção de plásticos, de aluminio, de fertilizantes e de petróleo com chumbo ${ }^{23}$.

A provável nova época geológica, ainda não reconhecida oficialmente pelas sociedades científicas ${ }^{24}$, tem como fundamento os impactos visíveis das atividades

20 CRUTZEN, P. J.; STOERMER, E. F. The Anthropocene. Global Change Newsletter, v. 41, p. 17-18, May. 2000. Eles são reconhecidos entre cientistas como os responsáveis pelo termo. Em 2011, The Economist havia publicado "Welcome to the Anthropocene", politizando o debate. WELCOME to the Anthropocene. The Economist, May, 2011. Disponível em: <http://www.economist.com/ node/18744401>. Acesso em: 23 mar. 2015. Ver também LEWIS, Simon L.; MASLIN, Mark A. Defining the Anthropocene. Nature News, n. 519, 171-180, 12 March 2015. MONASTERSKY, Richard. Anthropocene: the human age. Nature, n. 519, p. 144-147, 12 March 2015. Disponível em: <http://www.nature.com/news/anthropocene-the-human-age-1.17085> . Acesso em: 22 mar. 2015.

21 Dentre os maiores impactos, estão o aquecimento global, a elevação dos níveis oceânicos, a acidificação oceânica e a erosão da camada de ozônio. MONASTERSKY, Richard. Anthropocene: the human age. Nature, n. 519, p. 144-147, 12 March 2015. Disponível em: <http://www.nature.com/news/anthropocene-the-humanage-1.17085>. Acesso em: 22 mar. 2015. Tais impactos conduzem a diferentes propostas sobre o início do Antropoceno. Sobre impactos do clima, ver o Relatório do IPCC de 2014, AR5 Synthesis Report. INTERGOVERNMENTAL PANEL ON CLIMATE CHANGE. Chapter Climate Change 2014: Synthesis report, summary for policymakers. Disponível em: <http://www.ipcc.ch/pdf/assessment-report/ar5/syr/AR5_SYR_FINAL_SPM.pdf $>$. Acesso em: 22 mar. 2015.

22 Segundo Monastersky, tais testes nucleares deixaram uma camada radiotiva nos sedimentos geologicos. Apesar de Zalasiewicz entender que seria o "candidate for the lest-worst boundary", Finney alerta que nos fundos marinhos os ultimos 70 anos deixaram uma camada de sedimentos que não chega a um milimetro. MONASTERSKY, Richard. Anthropocene: the human age. Nature, n. 519, p. 144-147, 12 March 2015. Disponível em: < http://www. nature.com/news/anthropocene-the-human-age-1.17085>. Acesso em: 22 mar. 2015.

23 Crutzen sugeriu inicialmente a Revolução Industrial. Mas seu grupo Anthropocene Working Group analisou o periodo entre 1570 e 1620, quando os colonizadores Europeus exterminaram 50 milhões de indígenas nas Américas e a taxa de CO2 caiu significativamente. MONASTERSKY, Richard. Anthropocene: the human age. Nature, n. 519, p. 144-147, 12 March 2015. Disponível em: <http:// www.nature.com/news/anthropocene-the-human-age-1.17085>. Acesso em: 22 mar. 2015.

24 A Revista Nature, por exemplo, iniciou o ano de 2015 com vários artigos sobre o tema. 
humanas sobre o Planeta Terra. Certo é que se trata mais de uma necessária politização do problema da sustentabilidade da humanidade no longo prazo e de sua responsabilização, do que de questão puramente científica. Em outras palavras, importa transpor das ciências biológicas para os processos decisórios e regulatórios que os impactos causados pelas atividades humanas são insustentáveis.

Importante destacar também a coincidência dos fatores relatados acima e suas externalidades, ou seja, as crescentes taxas de poluição e a impunidade dos responsáveis, a exploração mal-regulada de recursos marinhos biológicos e minerais, a raridade de reparação aos danos causados ${ }^{25}$, países emergentes reformando a geopolítica ${ }^{26}$, necessidade de segurança energética e alimentar, fragilidade do regime de não proliferação nuclear, que tornaram-se os grandes desafios do Antropoceno e do direito do mar. De todo modo, nada impede o uso político e legal do conceito de Antropoceno para fins de mudanças comportamentais enquanto se espera um consenso científico mais consolidado, nos moldes do IPCC $^{27}$ e da Plataforma Intergovernamental de Biodiversidade e Serviços Ecossitêmicos (IPBES). Segundo especialistas das ciências exatas e biológicas, é possível monitorar as mudanças ecológicas e mostrar que tais atividades antrópicas estão influenciando de forma definitiva a evolução das espécies, o desaparecimento de outras, modificando a estrutura de redes tróficas marinhas em escala global ${ }^{28}$, no derretimento de geleiras e

25 PROST, Mario; TORRES, Camprubi. Against fairness? international environmental law, disciplinary bias and pareto justice. Leiden Journal of International Law, v. 25, n. 2, p. 379-396, 2012.

26 China tirou mais pessoas da pobreza, ou seja, vivendo com menos de um dólar norte-americano por dia, na última década do que todos os outros países juntos. China e India combinadas ainda têm mais pessoas vivendo abaixo da linha de pobreza do que todo o resto do mundo. Estima-se que a segurança energética e alimentar deles esteja diretamente ligada aos recursos marinhos no futuro próximo, como também dos demais países emergentes, que ainda exploram pouco tais recursos. No caso brasileiro, merece destaque também a ZOPACAS, zona livre de armas nucleares criada em função da liderança brasileira nas negociações e do consenso sobre a segurança nas duas costas do Atlântico. Resolução 41/11 da Assembléia Geral das Nações Unidas, de 1986.

27 Painel Intergovernamental sobre Mudança do Clima. Note-se que o 5 Relatorio nao aprofundou nas conclusões cientificas, pois foi decidido de se adotar a estrégia de consolidaçao das conclusoes do relatorio precedente para manter a legitimidade do processo.

28 Um estudo recente com 200 modelos de redes tróficas mostrou que entre 1880 e 2007 a sobrepesca conduziu a uma redução de dois terços da biomassa dos peixes predadores, induzindo a uma modificação das redes tróficas marinhas em escala global. CHRISTENSEN, V. et al. A century of fish biomass decline in the ocean. elevando o nível dos oceanos ${ }^{29}$, na ampliação de zonas mortas $^{30}$ nas zonas costeiras, como demonstrado abaixo, e em outros eventos climáticos extremos.

Figura 1 - Zonas mortas

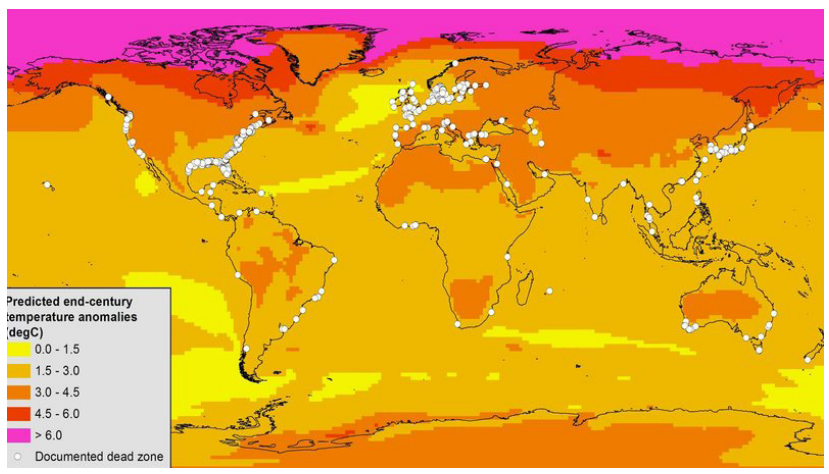

Fonte: <http://www.smithsonianmag.com/sciencenature/ocean-dead-zones-are-getting-worseglobally-due-climate-change-180953282/?no-ist>.

This map of known dead zones (white dots) shows how much annual air temperatures are expected to change by 2080-2099 compared with 1980-1999. (Keryn Gedan and Andrew Altieri/Smithsonian).

Nesse sentido, ante a irrefutabilidade dos impactos perigosos da atividade humana para o Planeta, cabe defender o início da nova ordem ambiental, que tornou-se global com o advento do Antropoceno, marcando o fim da ordem ambiental internacional descrita por Wagner Ribeiro, em 2001.

\section{A ORDEM AMBIENTAL GLOBAL}

Em 2007, Andrew Hurrell escreveu sobre a ordem global (política) ${ }^{31}$ e algumas mudanças importantes, in-

Marine Ecology Progress Series, n. 512, p. 155-166, 9 Oct. 2014.

29 Entre 1880 e 2009 o nível médio dos mares aumentou em cerca de $210 \mathrm{~mm}$. A taxa de elevação dos níveis dos mares a tendência a crescer, com um valor de $1.4+/-0.4 \mathrm{~mm} /$ ano desde os anos 1960. CHURCH, J.; WHITE, N. Sea-level rise from the late 19th to the early 21 st Century. Surveys in Geophysics, v. 32, n. 4/5, p. 585-602, sept. 2011.

30 "Dead zones" em inglês são as zonas paupérrimas em diversidade biológica, em função da poluição, acidificação, e dos impactos causados pela navegação, exploração e, mais recentemente, instalação de parques eólicos no litoral, entre outros. Sobre o clima, ver ZIELINSKI, Sarah. Ocean dead zones are getting worse globally due to climate change. Disponível em: <http://www.smithsonianmag.com/ science-nature/ocean-dead-zones-are-getting-worse-globally-dueclimate-change-180953282/?no-ist>. Acesso em: 21 mar. 2015.

31 HURRELL, Andrew. On global order: power, values, and the 
cluindo o fortalecimento de Estados não ocidentais ${ }^{32} \mathrm{e}$ mudanças profundas na ordem político-econômica ${ }^{33}$. Ele propos três quadros analíticos tomando-se por base os principais atores internacionais : os Estados soberanos, as instituições multilaterais e o fortalecimento de atores não estatais, como mercado e redes de atores cívicos. $\mathrm{Na}$ mesma época, foram definitivamente consolidados conceitos centrais para a diplomacia contemporânea, tais como : "zona econômica exclusiva", "plataforma continental", "áreas protegidas em alto-mar", "áreas protegidas além da jurisdição nacional ", "direito ambiental global"34, "regime global de diversidade biológica" 35 , " países emergentes"36, "powershift "37, "potências climáticas "38, "risco de falência sistêmica" "39, "Chinafrica"

Atualmente, convém argumentar que os Estados não conseguem cooperar de forma adequada para a regulação das relações internacionais; e as instituições multilaterais também escontram-se aquém do necessário para contribuir com a organização de legítima comunidade internacional, levando ao que se chama de crise do multilateralismo ${ }^{41}$. Infelizmente, na última década, a

constitution of International Society. Oxford: Oxford University Press, 2007.

32 IKENBERRY, John. The future of the liberal world order. internationalism after America. Foreign Affairs, New York, v. 90, n. 3, p. 56-68, May/June, 2011.

33 PRANTL, Jochen. Taming hegemony: informal institutions and the challenge to western liberal order. The Chinese Journal of International Politics, Oxford, v. 7, n. 4, p. 449-482, Winter, 2014.

34 YANG, T.; PERCIVAL, R. V. The emergence of global environmental law. 2009. Disponível em: <http://digitalcommons.law.scu.edu/ $\mathrm{cgi} /$ viewcontent. cgi? article $=1714 \&$ context $=$ facpubs, ou http: $/ /$ ssrn.com/abstract=1269157> . Acesso em: 21 fev. 2015.

35 INOUE, Cristina. Projetos de cooperação internacional, comunidades epistêmicas e conceito de regime global de biodiversidade : o caso de Mamirauá. In: CARVALHO, Maria Izabel; SANTOS, Maria Helena (Org.). O século 21 no Brasil e no mundo. São Paulo: Edusc, 2006

36 MORIN, Jean-Frédéric; ORSINI, Amandine. Essential concepts of global environmental governance. Abingdon: Routledge, 2014.

37 NYE, Joseph. Understanding 21st century power shifts. Disponível em: <http://www.europeanfinancialreview.com/?p=2743.June 24, 2011>. Acesso em: 21 fev. 2015.

38 VIOLA, Eduardo; FRANCHINI, Matías; RIBEIRO, Thaís. Sistema internacional de hegemonia conservadora: democracia e governança global na era da crise climática. São Paulo: Annablume, 2013.

39 Argumento empregado pelo Brasil para justificar a necessidade de reformas profundas no sistema ONU, principalmente no Conselho de Segurança, o qual não reflete mais a distribuição de poder mundial.

40 Sobre dado tema ver: CHINAAFRICA: accueil le magazine du nouveau monde. Paris: SLB, 2015. Disponível em: < http://www. chinafrica.info/\#home>. Acesso em: 24 fev. 2015.

41 Atualmente, estima-se que a Comissão de Limites da ONU cooperação multilateral não avançou satisfatoriamente, o que explica a lacuna entre os desafios de gestão e proteção de recursos marinhos por meio de ação coletiva, das quais o direito do mar consiste em exemplo emblemático.

Do ponto de vista dos atores internacionais, cabe destacar que a ordem internacional ambiental, construída ao longo do século XX, foi fortemente promovida pelos países desenvolvidos, principalmente os Europeus $^{42}$, mesmo que a história do direito marítimo seja diferente em alguns aspectos ${ }^{43}$. Para a gestão e proteção dos recursos marinhos, as principais instituições multilaterais são: a Assembleia Geral da ONU (AGNU), Autoridade Internacional para os Fundos Marinhos (AIFM), Tribunal do Mar (ITLOS), Comissão de Limites da Plataforma Continental (CLPC), Programa das Nações Unidas para o Meio Ambiente (PNUMA), Organização Marítima Internacional (OMI), Organização das Nações Unidas para a Educação, a Ciência e a Cultura (UNESCO), Processo informal e consultativo da ONU sobre oceanos e direito do mar (UNICPOLOS) ${ }^{44}$ e também a Comissão Mundial de Áreas Protegidas (CMAP), Fundo Mundial para a Natureza (WWF) e a International Union for Conservation of Nature (IUCN).

leve mais de vinte anos para analisar as novas demandas, por exemplo. Para o caso brasileiro, ver FIGUEIRÔA, Christiano Sávio Barros. Limites exteriores da plataforma continental do Brasil conforme o direito do mar. Brasilia: Fundação Alexandre de Gusmão/MRE, 2014. Disponível em: <http://funag.gov.br/loja/download/1100-Limites_ exteriores_da_plataforma_continental_do_Brasil_conforme_o_Direito_do_Mar.pdf>. Acesso em: 22 mar. 2015.

42 BOULET, Romain; BARROS-PLATIAU, Ana; MAZZEGA, Pierre. 35 years of multilateral environmental agreements ratifications: a network analysis. In: INTERNATIONAL WORKSHOP "NETWORK ANALYSIS IN LAW, 2, 2014, Krakow. Anais... Cambridge: Harvard College, 2014. No prelo.

43 As análises das ratificações das convenções demonstra diferenças interessantes entre o direito ambiental e o direito marítimo, que não podem ser tratadas no escopo desta análise por uma questão de foco. Os países desenvolidos demoraram mais a ratificar a UNCLOS do que aqueles em desenvolvimento. Austrália e Alemanha foram os primeiros países desenvolvidos a ratificar em 1994, após a ratificação de 64 países em desenvolvimento. UNITED NATIONS. Division for Ocean Affairs and the Law of The Sea. Chronological lists of ratifications of, accessions and successions to the Convention and the related Agreements as at 3 October 2014. Jan. 2015. Disponível em: <http://www. un.org/Depts/los/reference_files/chronological_lists_of_ratifications.htm\#Agreement for the implementation of the provisions of the Convention relating to the conservation and management of straddling fish stocks and highly migratory fish stocks $>$. Acesso em: 21 mar. 2015.

44 UN Open-ended Informal Consultative Process on Oceans and the Law of the Sea. 
A ordem ambiental global é, por sua vez, definitivamente marcada pela irupção de atores não estatais, ou atores privados, principalmente do setor econômico, comercial e tecnológico. No caso do mar, o setor petroleiro é extremamente relevante ${ }^{45}$. Diferentemente das análises que os separavam, na ordem global os setores públicos e privados estão cada vez mais imbricados, como havia assinalado Edith Brown-Weiss em $1998^{46}$.

Entretanto, conceitos como "ordem internacional" $\mathrm{e}$ "sociedade internacional" continuam prevalecendo na teoria de relações internacionais, sobretudo para autores que consideram o Estado como principal ator. No Brasil, a obra de Wagner Ribeiro sobre a ordem internacional ambiental, de 2001, ainda é excelente referencial, rica de reflexões ainda pertinentes. Contudo, este artigo adota o conceito de ordem ambiental global, marcando definitivamente o fim da ordem internacional por meio de mudança paradigmática que abre novas possibilidades de análise.

Primeiro, leva em conta o impacto da mudança de época geológica causada pelas atividas antropocêntricas. Impacto este que deveria ser estimado na assunção da obrigação positiva do Estado de proteger o meio ambiente em geral, e o marinho em particular, por ser o menos protegido e cada vez mais vulnerável e cobiçado. Segundo, evita a repetição infinita do termo "nova ordem internacional", haja vista sua utilização com o fim do sistema internacional bipolar ápos o desmoronamento do bloco soviético. Novos desafios elencados acima constituem uma terceira razão, notadamente no que concerne aos impactos climáticos, descritos no Relatório AR5 do Painel Intergovernamental sobre $\mathrm{Mu}$ danças do Clima (IPCC) publicado em março de 2015. Por fim, as atividades humanas mais inovadoras e às vezes mais perigosas, como a prospecção de petróleo e minerais em águas profundas, pesca em larga escala, transporte de material radioativo, exploração de zonas polares $^{47}$, produção de energia, biopirataria e turismo de

45 No caso brasileiro, representantes da Petrobrás participam ativamente da política nacional sobre recursos marinhos e dos debates interinstitucionais. Em outros países, o setor petroleiro, mesmo quando privado, pode ter forte influência nos processos decisórios. 46 BROWN WEISS, Edith. The changing structure of iternational law. In: PRIEUR, M.; LAMBRECHTS, C.(Ed.). Les hommes et l'environnement: quels droits pour le XXIe siècle? Etudes en hommage à Alexandre Kiss. Paris: Frison-Roche, 1998.

47 MARQUES, Fabrício. Corrida sobre o gelo. Disponível em: $\quad<$ http://www.revistapesquisa.fapesp.br/wp-content/uploads/2012/04/032-037_1941.pdf?f0d91f>. Acesso em: 25 mar. 2015 . massa são alguns exemplos que se somam aos tradicionais desafios de poluição, perda de diversidade biológica, sobrepesca de algumas espécies e pirataria ${ }^{48}$. Assim, mesmo não oferecendo uma lista exaustiva de desafios relativamente recentes como o Antropoceno, fica claro que a governança dos oceanos tornou-se muito mais complexa em termos científicos e tecnológicos também.

Dois pontos completam a lista e caracterizam a ordem global ambiental, e portanto merecem debate mais aprofundado no escopo deste artigo: a complexidade da governança dos oceanos e a lenta evolução do direito do mar.

\section{A COMPLEXIDADE DA GOVERNANÇA DOS OCEANOS}

Com o acirramento da corrida por recursos marinhos, aumenta esponencialmente a complexidade ${ }^{49}$ da governança dos oceanos. Como exposto acima, aumentaram os interesses dos Estados, os meios tecnológicos, os desafios de regulação e a necessidade de ação coletiva institucionalizada para a sua efetiva regulação e controle. Por isso, o conceito de complexidade torna-se central.

Naturalmente, a governança dos oceanos implica a partipação de diversos tipos de atores, como os Estados, com suas perrogativas exclusivas de regulação normativa ; as empresas, indo das multinacionais às locais ; e os mais diversos atores da sociedade civil. Pensar nos usuários nos levaria ao fato que quase metade da população mundial vive a menos de $150 \mathrm{~km}$ da zona $\operatorname{costeira}^{50}$. Mesmo sem evocar uma teoria de poder, fica claro que cada ator ocupa espaço específico na estrutura e controla uma parte mais ou menos importante dos

48 MICHAEL, J. et al. Navigating the maritime piracy regime complex. Global Governance: a review of multilateralism and international organizations, v. 19, n. 1, p. 93-104, Jan./March, 2013. Os autores demonstram o papel central do setor privado nos debates e a ausência de um "norm entrepreneur" forte.

49 Sobre a complexidade normativa, ver: BOURCIER, Danièle; MAZZEGA, Pierre; BOULET, Romain. Visualizer la compléxité du droit. Disponível em: <https://pierremazzega.files.wordpress. com/2010/02/2009bourcieretal-bruylant.pdf > . Acesso em: 23 mar. 2015.

50 Em 2010 o UN Atlas revelou: "44 percent of us live in coastal areas". SIIRILÄ, Erkki. UN Atlas: 44 percent of us live in coastal areas. Jan. 2010. Disponível em: <http://coastalchallenges. com/2010/01/31/un-atlas-60-of-us-live-in-the-coastal-areas / >. Acesso em: 23 mar. 2015. 
instrumentos que orientam as tomadas de decisão, bem como a definição da natureza e do conteudo das medidas implementadas (políticas públicas, regulação jurídica, econômica ou acordos de cooperação por exemplo). Em outros termos, a natureza das relações dos atores depende profundamente do status, papel e interesses de cada um deles.

Tal miríade de interações, denominada "governança em redes" 51 atravessa em todos os sentidos os "estratos" da organização política (do global ao local, o que corresponde à imagem da ordem “ ultrapassada ") e conduz à ideia de sistema, ou de sociedade. Contudo, o sistema apresenta vários traços de complexidade : a) ele é aberto, imerso num sistema mais vasto e sem limites definidos (interferências com esferas do comércio, da segurança, das finanças etc.) ; b) ele se auto-organiza dinamicamente por meio de ações executadas e de sua estrutura evolutiva ; c) os efeitos que ele induz são muito pouco previsíveis, menos ainda no médio e longo prazos; d) é dificil se produzir uma " imagem ", um conhecimento preciso em dado momento, e caso seja possível, tal conhecimento já nasceria parcialmente obsoleto.

Eis algumas razões que nos conduzem a buscar novas formas de governança dos oceanos : estabelecer regras simples entre os atores elementares de modo que emerja em seguida de suas interações individuais o resultado esperado (preservação dos recursos marinhos vivos, gestões racionais e equitativa dos recursos marinhos minerais, dos espaços etc.). Tal emergência integra necessariamente a interpretação de regras pelos atores e o uso que delas fazem ${ }^{52}$. No futuro, essa questão será central a qualquer reflexão para tornar o direito do mar instrumento legítimo e eficaz, congruente com os desafios do desenvolvimento sustentável das nossas sociedades.

Do ponto de vista da complexidade, surge a seguinte questão : os modos tradicionais de regulação são bem

51 CARLSSON, L.; SANDSTRÖM, A. Network governance of the commons. International Journal of the Commons, v. 2, n. 1, p. 33-54. 2008. Ver também HUPPÉ, G. A.; CREECH, H.; KNOBLAUCH, D. The frontiers of networked governance. IISD Report, The International Institute for Sustainable Development, $40 \mathrm{p}$. 2012. Disponível em: < http://www.iisd.org/publications/frontiersnetworked-governance $>$. Acesso em: 22 mar. 2015.

52 PITT, J.; SCHAUMEIER, J.; ARTIKIS, A. The axiomatisation of socio-economic principles for self-organising systems. ACMTransactions on Autonomous and Adaptive Systems, v. 7, n. 4, p. 1-39, Dec. 2012. Disponível em: <http://dx.doi.org/10.1145/2382570.2382575>. Acesso em: 22 mar. 2015. adaptados aos desafios ambientais contemporâneos? Precisamente em termos de resultados, três argumentos fundamentais e interligados nos conduzem a certo ceticismo relativo à eficiência da atual abordagem de regulação dos espaços e dos recursos marinhos ${ }^{53}$. Primeiro, as abordagens correntes da governança negligenciam um fato essencial aos problemas ambientais, ou seja, que uma parte da mediação entre atores não é realizada por meios institucionais e políticos, mas pelos próprios atores independentemente. Os recursos marinhos (e em boa medida o meio ambiente marinho) são rivais : ao modificar o estado deles (por exemplo quantitativo : estoques ; qualitatvo: poluição), cada ator muda as condições de acesso e de uso (e podemos adicionar de regulação) dos mesmos recursos pelos outros atores. Por outro lado, os recursos "impõem” as leis fisico-químicas e biológicas da sua própria evolução (dinâmicas ecológicas, climáticas, distribuição espacial de recursos herdade da história geológica etc. $)^{54}$. Enfim, certos recursos, notadamente aqueles vivos, não são exclusivos, ou dificilmente o são. A criação de ZEE tende a resolver o problema por meio de regulação negociada. Entretanto, no caso de recursos vivos, como os estoques de peixes ${ }^{55}$, o respeito às regras é difícil de se garantir. Pelo menos duas propriedades genéricas identificadas como indispensáveis à preservação de um bem comum não são asseguradas ${ }^{56}$ : a) a identificação clara de delimitação do reservatório de recursos e quem tem direito ao seu uso ${ }^{57}$; b) a possibilidade de assegurar (a custo viável) monitoramento do estado do recurso e vigilância do comportamento dos usuários.

Tomando em consideração essas fortes incertezas cognitivas, os atores (decisores, reguladores, usuários etc.) desenvolvem estratégias comportamentais baseadas sobre preferências em evolução constante, e crenças regularmente revisitadas, como processos de aprendiza-

53 OSTROM, ELinor. Coping with the tragedy of the commons. Annual Review of Political Science, v. 2, p. 493-535, June 1999.

54 Esta simples constatação opõe uma franca reprovação ao que de acordo com o Discurso do Método (1637) de René Descartes tornou-se um tipo de máxima de um certo projeto de desenvolvimento : "se rendre comme maitre et possesseur de la nature."

55 Ver A política comunitária para pesca. COMISSÃO EUROPÉIA. A politica comum das pescas: gestão das pescas na UE. Disponível em: < http://ec.europa.eu/fisheries/cfp/index_pt.htm>. Acesso em: 22 mar. 2015.

56 OSTROM, Elinor. Governing the commons: the evolution of institutions for collective action. Cambridge: Cambridge University Press, 1990.

57 Como o paradigma clássico do "passageiro clandestino" (freerider) de Olson, 1971. 
do sobre os efeitos das suas respectivas posições estratégicas em relação aos demais atores. ${ }^{58}$ Isto é, particularmente verdadeiro para os Estados que integram alianças mais ou menos efêmeras, como G20, ZOPACAS e BRICS, pois mesmo que discutam de outras agendas como do comércio ou da segurança - têm incidência sobre suas ambições ambientais.

Levando-se em consideração as três grandes categorias de atividades humanas nos oceanos, a saber : navegação, pesca e mineração, não é dificil argumentar a complexidade da regulação internacional e o grande potencial de conflitos de interesses. Voltando-se ao contexto de assimetria econômica e tecnológica com a emergência de economias grandes em países ainda em desenvolvimento, a questão torna-se ainda mais interessante para futuras pesquisas. Dessa feita, a complexidade político-legal é construída por mecanismos de comando e controle, normalmente top-down, ou seja, estabelecidos em nível internacional ou regional e depois internalizados, sem que haja sistematicamente a garantia das condições necessárias para sua respectiva aplicação interna, como se discutirá a seguir.

\section{A eVOLUÇão do DIREITO do MAR}

Em termos amplos, a história do direito do mar pode ser descrita pela liberdade de navegação e do regime "first arrived first served" dos séculos anteriores ao XVII, seguida de sua lenta restrição no século XVIII com o conceito de mar territorial e o uso recorrente do direito consuetudinário. No século XIX, os contenciosos no Mar de Bering reforçaram a restrição à liberdade dos mares. No mesmo sentido, a maior regulação das atividades de navegação, pesca e mineração ao longo do

58 O estudo deste tipo de "wicked problems" dispõe de um quadro de análise na interface entre ciências políticas. FUNTOWICZ, S. O.; RAVETZ, J. R. Science for the post-normal age. Futures, v. 25, n. 7, p. 739-755, Sept. 1993. HEAD, B. W.; ALFORD, J. Wicked problems: implications for public policy and management. Administration and Society, v. 20, n. 10, p. 1-29, Mar. 2013. Disponível em: <http:// aas.sagepub.com/content/early/2013/03/27/0095399713481601. full.pdf>. Acesso em: 22 mar. 2015. E teoria da decisãoem KØRNØV, L.; THISSEN, W. A. H. Rationality in decision- and policy-making: implications for strategic environmental assessment. Impact Assessment and Project Appraisal, v. 18, n. 3, p. 191-200, 2010. e SHEPHERD, N. G.; MAYNARD, R. The influence of context on the strategic decision-making process: a review of the literature. International Journal of Management Reviews, v. 16, n. 3, 2014, p. $340-$ 364, 2014. século XX foi marcada pelo interesse geral em limitar a apropriação de recusos fora de jurisdições nacionais, a exploração excessiva de recursos halieuticos, e a poluição. No caso dos navios, os artigos 217, 218 e 220 da UNCLOS marcaram o fim do regime exclusivo da bandeira do Estado $^{59}$, por exemplo.

No passado foi difícil iniciar o debate sobre como regular atividades fora das jurisdição nacional dos países membros do sitema $\mathrm{ONU}^{60}$, porém, atualmente, há consenso relativamente consolidado sobre o interesse geral da humanidade e a necessidade de regulação conjunta para garantir às gerações futuras o direito de ter acesso a recursos que existem hoje, formando o cerne do que se convencionou chamar princípio do desenvolvimento sustentável. Menos louvável porém mais realista, a verdadeira motivação de grande parte dos Estados consiste em evitar que uns aproveitem mais do que os outros dos recursos marinhos em alto-mar, apreensão generalizada de países costeiros e ilhas em relação às potências tecnológicas ${ }^{61}$, cujo sucesso mais conhecido foi a proposta na ONU do então embaixador Pardo, maltês, que levou ao conceito de patrimônio comum da humanidade ${ }^{62}$.

Se o direito dividia os bens sem dono em res nullius e res communis, os avanços tecnológicos colocam em xeque muitas das certezas jurídicas construídas ao longo do século $\mathrm{XX}^{63}$. Atualmente, consolida-se o interesse geral na gestão coletiva de bens comuns, e nenhum Estado pode explorar os fundos marinhos sem despertar interesse ou preocupação de outros Estados. Exemplo disso, nota-se em relação a uma interpretação cada vez mais restritiva do princípio da soberania ${ }^{64}$ e do direito

59 SCOVAZZI, Tullio. Marine protected areas on the high seas: some legal and policy considerations. The International Journal of $\mathrm{Ma}$ rine and Coastal Law. v. 19, n. 1, p. 01-17, 2004.

60 CHURCHILL, R. R.; LOWE, A. V. The law of the sea. 3. ed. Manchester: University Press, 1999.

61 De forma geral, potências tecnológicas são os países desenvolvidos, que investiram muito na prospecção marinha de recursos vivos e não vivos. Países emergentes integram cada vez melhor a lista, notadamente a China, e outros países em desenvolvimento tem ambições desmesuradas, como no caso da Antártida.

62 KISS, Alexandre. Droit international de l'environnement. Paris: A. Pedone, 1989.

63 GAJA, Giorgio. The protection of general interestsin the international community. Leiden: Brill, 2013. (The Hague Academy collected courses online, 364).

64 SASSEN, Saskia. Losing control? Sovereignty in the age of globalization. New York: Columbia University Press, 2015. Trata da proliferação de códigos e instituições nos regimes internacionais de direitos humanos e comerciais que desafiam o princípio basilar 
inocente de passagem nos mares, bem como uma interpretação mais atualizada do direito costumeiro ${ }^{65}$. A pesca em alto-mar é um caso interessante, bem como no caso de outros animais migratórios de longas distâncias e das baleias. Entretanto, como mencionado, a evolução do direito internacional ambiental em geral e marítimo em particular é muito mais lenta do que as mudanças ambientais, políticas e econômicas desde a década de 1970. Em 1989, Martine Rémond-Goullioud ${ }^{66}$ já havia explicado que a evolução institucional é por definição lenta, visto que consiste em reação às mudanças sociais e ambientais. Consequentemente, o regime legal para o alto-mar é incompleto e inadequado para atingir o objetivo de gestão e proteção dos recursos. As lacunas que limitam sua efetividade, são de governança, regulatória, substantivae de implementação ${ }^{67}$.

Atualmente, apesar das divisões em várias areas, direito ambiental, comercial, maritimo, nuclear, direitos humanos, direito dos transportes, entre outros, e o direito privado, é importante pensar em conceitos que permitam algum tipo de integração, ou ao menos, de circulação de normas, no sentido que as boas práticas já implementadas alhures podem ser adaptadas para outras realidades politico-legais. Um deles é sem dúvida o conceito de "complexo de regimes" como um conjunto de regimes específicos colocados junto de forma desordenada ${ }^{68}$. Dentre os elementos destacados para o

da soberania nacional. OLIVEIRA, Liziane. A convenção sobre diversidade biologica e o principio de soberania nacional. 2006. 176 f. Dissertação (Mestrado em Direito) - Faculdade de Direito, Universidadede Brasilia, Brasília, 2006. ALFAIA JR., José Roberto. Reclamar ou intervir? As obrigações positivas do estado em situações de desastre ambiental. 2014. f. Tese (Doutorado) - Instituto de Relações Internacionais, Universidade de Brasília, Brasília, 2014.

65 "The present challenges of international law of the sea are to be found in the practical capacity of States to adapt and change old principles to conform with new needs". SCOVAZZI, Tullio. Direito internacional público. Haia: Academia de Direito da Haia, 2000. p. 232. 66 REMOND-GOUILLOUD, M. Du droit de détruire. Paris: Universitaires de France, 1989.

67 RAYFUSE, R.; WARNER, R. M. Securing a sustainable future for the oceans beyond national jurisdiction: the legal basis for an integrated cross-sectoral regime for high seas governance for the 21st century. International Journal of Marine and Coastal Law, v. 23, n. 3, p. 399-421, 2008.

68 "which are loosely coupled sets of specific regimes". KEOHANE, Robert O.; VICTOR, David G. The regime complex for climate change. Perspectives on Politics, v. 9, n. 1, p. 7-23, Mar, 2011. Disponível em: <http://ilar.ucsd.edu/assets/001/501988.pdf>. Acesso em: 22 mar. 2015. RAUSTIALA, Kal; VICTOR, David G. The regime complex for plant genetic resources. International Organization, v. 58, p. 277-309, Spring 2004. DREZNER, Daniel W. The power and peril of international regime complexity. Perspectives on caso do clima e que podem ser retomados para o caso da governança dos oceanos, estão os regimes legais sob auspício da ONU, acordos bilaterais e regionais, relatórios de autoridades científicas (experts), grupos como o G20, políticas subnacionais, e mais distante, regras econômicas e comerciais. Keohane e Victor defendem que o complexo de regimes permite maior flexibilidade e capacidade adaptativa, posto que a organização da arquitetura da governança seria simplificada. Ao contrário, Orsini, Morin e Young defendem que o complexo de regimes pode criar obstáculos ou oportunidades, dependendo se são fragmentados, centralizados ou den$\operatorname{sos}^{69}$. No caso do complexo de regimes do mar, que é indubitavelmente fragmentado ao extremo tanto do ponto de vista setorial quanto geográfico, e determina o sucesso da governança oceânica, pode-se argumentar que a circulação de normas não é apenas imprescindível, mas urgente. Sabendo-se que uma governança oceânica centralizada ou unificada não passa de ideal político-legal, defende-se neste artigo que os espaços convencionais tenham ao menos um framework conceitual forte, como foi ambição da UNCLOS e da CDB, e que as obrigações internacionais por eles determinadas sejam compatíveis entre eles, na medida do possível.

\subsection{A necessária circulação de normas}

A literatura especializada em direito internacional ambiental e relações internacionais tende a descrever a complexidade da governança ambiental em termos da fragmentação e da sobreposição de regimes ${ }^{70}$ e normas. Em termos amplos, a Comissão da ONU sobre Direito Internacional abordou o problema na publicação "Fragmentation of international law: difficulties arising from the diversification and expansion of international law" "71. No mesmo sentido, Daillier e Pellet afirmaram que o direito internacional ambiental era uma " colcha

Politics, v. 7, n. 1, p. 65-70, Mar. 2009.

69 ORSINI, Amandine; MORIN, Jean- Frédéric; YOUNG, Oran. Regime complexes: a buzz, a boom, or a boost for global governance? Global Governance, v. 19, n. 1, p. 27-39, Jan./Mar. 2013. 70 Para a teoria de relações internacionais, ver a obra de Oran Young nos últimos vinte anos sobre as questões ambientais.

71 KOSKENNIEM, Martti. Fragmentation of international law: difficulties arising from the diversification and expansion of international: report of the study group of the International Law Commission. 13 Apr. 2006. Disponível em: < http://legal.un.org/ilc/ documentation/english/a_cn4_1682.pdf>. Acesso em: 27 mar. 2015. 
de retalhos "72; Sandrine Maljean-Dubois destacou a ausência de hierarquia entre espaços convencionais ${ }^{73}$; Mireille Delmas-Marty ${ }^{74}$ publicou ampla pesquisa sobre o pluralismo jurídico ordenado em termos de atores, fatores e processos; Mario Prost destacou as lacunas do direito internacional ${ }^{75}$; e Marcelo Dias Varella se dedicou ao estudo da internacionalização do direito e sua complexidade $^{76}$. A lista de pesquisadores é longa, refletindo a pesquisa internacional publicada nas últimas duas décadas. No caso específico do mar, o ecossistema marinho e o costeiro foram abordados em capítulos separados até no Millenium Ecosystem Assessment ${ }^{77}$, apesar das relações fortes entre eles.

Todavia, se de um lado observa-se a fragmentação da governança ambiental, observa-se igualmente, nos últimos anos, o aparecimento de mecanismos e processos político-legais que permitem certa coerência entre regimes coexistentes, a ampliação do diálogo entre operadores de direito e processos de transposição de normas, o que se define neste artigo como "circulação de normas" "78. Diversos são os mecanismos e processos que permitem tal circulação e conduezm aos tratados multilaterais, tais como os atores, as agendas de negociação, os princípios jurídicos, e os conceitos estruturantes, como o de interesse geral da humanidade.

No caso da proteção da biodiversidade no mar, por exemplo, merecem destaque a Convenção sobre Diver-

72 DAILLIER, Patrick; PELLET. Alain. Droit international public. Paris: LGDJ, 2002.

73 MALJEAN-DUBOIS, Sandrine. La mise en oeuvre du droit international de l'environnement. Paris: IDDRI, 2003. (les Notes de L'iddri, n. 4) Disponível em: <http://www.peacepalacelibrary.nl/ebooks/ files/337934460.pdf>. Acesso em: 27 mar. 2015.

74 DELMAS-MARTY, Mireille. Les forces imaginantes du droit: le pluralisme ordonné. Paris: Seuil, 2006.

75 PROST, Mario. Unitas multiplex: unites et fragmentations en droit international. Bruxelles: Bruylant, 2013.

76 VARELLA, Marcelo. Internationalization of law: globalization, international law and complexity. Brasília: Centro Universitário de Brasília, 2013.

77 HASSAN, Rashid; SCHOLES, Robert; ASH, Neville. Ecosystems and human well-being: current state and trends: findings of the Condition and Trends Working Group. Washington: Millennium Ecosystem Assessment, 2005. (The Millennium Ecosystem Assessment Series; v. 1). Disponível em: <http://www.millenniumassessment.org/en/Condition.html>. Acesso em: 27 mar. 2015.

78 Esta seção é fortemente baseada dos resultados de pesquisa do projeto CIRCULEX iniciado em 2013, financiado pela ANR francesa e sob a direção de Sandrine Maljean-Dubois. MALJEAN-DUBOIS, Sandrine. La mise en oeuvre du droit international de l'environnement. Paris: IDDRI, 2003. (les Notes de L’iddri, n. 4) Disponível em: <http:/ / www.peacepalacelibrary.nl/ebooks/files/337934460.pdf>. Acesso em: 27 mar. 2015. sidade Biologica (CDB, 1992), a Convenção das Nações Unidas sobre o Direito do Mar sobre a Conservação e Ordenamento de Populações de Peixes Transzonais e de Populações de Peixes Altamente Migratórios (Convenção de Montego Bay, 1982), Convenção de Bona sobre a Conservação das Espécies Migradoras Pertencentes à Fauna Selvagem (1979), Convenção sobre o Comércio Internacional de Espécies da Fauna e Flora Selvagem em Perigo de Extinção (CITES,1973), Tratado da Antártida (1959), Convenção de Genebra sobre a Pesca e a Conservação de Recursos Vivos do Alto Mar (1958). Além disso, houve proliferação significativa de convenções regionais e convenções setoriais sobre a poluição marinha e a pesca principalmente, das quais podem-se destacar o Protocolo Relativo a Áreas Especialmente Protegidas e Diversidade Biológica no Mediterrâneo (1995).

Finalmente, os debates sobre recursos situados além da jurisdição nacional ganharam novo alento ${ }^{79}$. Cada tratado tem uma história própria, e impõe obrigações que nem sempre são compatíveis com uma visão sistêmica dos desafios atuais. Certamente, os regimes internacionais não são independentes dos interesses dos Estados que os promoveram, ou seja, os espaços convencionais acima foram, em larga medida, codificados sob a liderança de potências marítimas tradicionais, as mesmas que construiram a ordem ambiental internacional ao longo do século passado. Ademais, destaque-se a necessidade de incluir atores subnacionais nos processos regulatórios ${ }^{80}$.

Nesse sentido, a circulação de normas deve ser entendida como resultado de algo bem mais amplo, que é a abordagem da questão do mar como um sistema vivo que interage com a zona costeira e com a terrestre ${ }^{81}$.

79 Ad Hoc Open-ended Informal Working Group to study issues relating to the conservation and sustainable use of marine biological diversity beyond areas of national jurisdiction, paragrafo $73 \mathrm{da}$ résolução 59/24 da AGNU. UNITED NATIONS. Resolution adopted by the General Assembly, 4 of February of 2005. Oceans and the law of the sea. Disponível em: <http://www.unga-regular-process.org/ images/Documents/un\%20a-res-59-24.pdf>. Acesso em: 22 mar. 2015. Ver também UNITED NATIONS. Oceans and the law of the sea: letter dated 25 July 2014 from the Co-Chairs of the Ad Hoc Open-ended Informal Working Group to the President of the General Assembly. Disponível em: <http://www.un.org/depts/los/ biodiversityworkinggroup/documents/BBNJreport_69_177.pdf $>$. Acesso em: 22 mar. 2015.

80 Dois casos interessantes: o estado da California nos EUA e do estado de São Paulo no Brasil, que atuam de forma crescentemente independente de suas respectivas diplomacias.

81 Um exemplo central e ao mesmo tempo complexo, foi demon- 
Ademais, concentra diversos ramos do direito, e uma vasta diversidade de atores, do federal ao local no caso brasileiro. Ela é necessária, ou seja, não opcional, como primeiro passo para uma reforma maior do regime legal global, para torná-lo mais integrado e trans-setorial ${ }^{82}$. No caso do Brasil, no mesmo sentido, o ordenamento nacional precisa ser discutido com base na fragmentação atual ${ }^{83}$ e da circulação de normas internacionais, regionais, nacionais e sub-nacionais, que inclua também os atores locais, como as comunidades de pesca.

\subsection{A estratégia brasileira de gestão e proteção dos recursos marinhos}

Por sua megadiversidade biológica e a riqueza mineral, o Brasil tem o duplo desafio de gestão e proteção dos recursos ambientais sob sua tutela, mas também fora de sua jurisdição. Nesse sentido, impõe-se a questão relativa aos desafios relativos à navegação, pesca e mineração, notadamente a poluição, sobrepesca, biopirataria e a bioinvasão ${ }^{84}$, bem como práticas diversas que causam danos ao meio ambiente marinho e costeiro. Ademais, como salientou Figuerôa:

strado que a ausencia de eventos climaticos extremos na costa brasileira é relativa aos serviços ambientais ecossitemicos, como os amazônicos. NOBRE, Antônio. O futuro climático da Amazônia: relatório de avaliação científica. São José dos Campos: ARA, 2014. Disponível em: <http://www.ccst.inpe.br/wp-content/uploads/2014/10/Futuro-Climatico-da-Amazonia.pdf>. Acesso em: 22 mar. 2015.

82 "In view of escalating threats to the oceans from existing and emerging uses and form the impacts of climate change, transformation to a legal regime better suited to integrated, cross-sectoral management and preservation of vital ocean ecosystem services and resilience may no longer be a luxury, but rather a necessity.".

83 In Oliveira, Carina Costa de e Coelho, Luciana. Os limites do planejamento da ocupação sustentável da zona costeira brasileira. Revista de Direito Internacional, vol.12, no.1. (nesta edição).

84 "Bioinvasão ou invasão biológica é o ato ou efeito de um ou mais organismos invadirem e se estabelecerem em ambientes onde não haviam registros anteriores para a espécie. Entretanto, existem dois tipos de invasões: expansões e introduções. As expansões consistem na dispersão de organismos por mecanismo natural e as introduções ocorrem quando as espécies são transportadas por atividades humanas, intencionalmente ou não, para uma área onde não ocorriam". SOUZA, Rosa Cristina de. Água de lastro: uma ameaça à biodiversidade. In: REUNIÃO ANUAL DA SBPC, 62, 2010, Natal. Ciências do mar: herança para o futuro, Anais... Natal: SBPC, 2010. Disponível em: < http://www.sbpcnet.org.br/livro/62ra/mesas_redondas $/ \mathrm{MR} \% 20$ Rosa $\% 20$ Cristina $\% 20$ Corr $\%$ C $3 \%$ AAa $\% 20$ Luz\%20de\%20Souza.pdf>. Acesso em: 02 abr. 2015. Ver também: OLIVEIRA, C. C. Critérios jurídicos para a responsabilidade civil decorrente de bioinvasão: o caso do coral-sol. A Ressurgência, Niterói, v. 7, p. 21-22, 2013.
A importância econômica e estratégica para o país da extensão da plataforma continental além das $200 \mathrm{M}$ elevou-se significativamente. Atualmente os blocos do pré-sal em atividade comercial na plataforma continental brasileira estão muito próximos das $200 \mathrm{M}$ de nossas linhas de base, a 50 $\mathrm{km}$ desse limite. ${ }^{85}$

Oficialmente,

o Brasil dispõe de estratégia e política nacional que abrangem os temas principais relacionados a oceanos, mares e zonas costeiras, incluindo seus recursos naturais, vivos ou não-vivos. A Política Nacional para os Recursos do Mar (PNRM), aprovada por Decreto Presidencial de 12 de maio de 1980 , tem como propósitos a promoção da integração do mar territorial, da zona econômica exclusiva e da plataforma continental ao espaço brasileiro, e a exploração racional e o uso sustentável dos recursos do mar. Compreendidos como recursos vivos, minerais, energéticos e biotecnológicos da coluna de água, solo e subsolo marinho, que apresentem interesse para o desenvolvimento econômico e social do País, além de sustentabilidade ecológica. ${ }^{86}$

A Comissão Interministerial para os Recursos do Mar (CIRM) ${ }^{87}$ é vinculada ao Ministério da Defesa, composta por Ministérios da Defesa, Relações Exteriores, Minas e Energia, Agricultura, e Transportes, sua finalidade é

Submeter ao Presidente da República, por
intermédio do Ministro de Estado da Defesa, as
diretrizes propostas para a consecução da PNRM;
Apreciar o planejamento de atividades relacionadas
com os recursos do mar, propondo ao Presidente
da República prioridades para os programas e
projetos que o integram; Coordenar a elaboração
de planos e programas plurianuais e anuais, comuns

$85{ }^{86}$ FIGUEIRÔA, Christiano Sávio Barros. Limites exteriores da plataforma continental do Brasil conforme o direito do mar. Brasilia: Fundação Alexandre de Gusmão/MRE, 2014. Disponível em: <http:// funag. gov.br/loja/download/1100-Limites_exteriores_da_plataforma_ continental_do_Brasil_conforme_o_Direito_do_Mar.pdf >. Acesso em: 22 mar. 2015.

86 BRASIL. Ministério do Meio Ambiente. Diversidade biológica marinha e costeira. Disponível em: <http://www.mma.gov.br/estruturas/chm/_arquivos/2relat_cap1_Marinha.pdf>. Acesso em: 22 mar. 2015.

87 Segundo a Marinha: "A Comissão Interministerial para os Recursos do Mar (CIRM), criada pelo Decreto no 74.557, de 12 de setembro de 1974, revogado pelo Decreto no 3.939 , de 26 de setembro de 2001, alterado pelos Decretos nos: 4.815 , de 20 de agosto de 2003; 6.107, de 2 de maio de 2007; 6.484, de 17 de junho de 2008; 6.756, de 2 de fevereiro de 2009 e 6.979 , de 8 de outubro de 2009 tem a finalidade de coordenar os assuntos relativos à consecução da Política Nacional para os Recursos do Mar (PNRM)". BRASIL. Comissão Interministerial para os Recursos do Mar. Seja bem-vindo ao nosso site. Disponível em: <http:/ / www.mar.mil.br/secirm/portugues/principal.html>. Acesso em: 22 mar. 2015. 
e setoriais; Sugerir as destinações de recursos financeiros para incrementar o desenvolvimento das atividades relacionadas com o mar e com a Antártica, por meio de dotações orçamentárias ou de outras fontes, internas ou externas; Acompanhar os resultados e propor as alterações da PNRM; Acompanhar os resultados e propor as alterações na execução do Programa Antártico Brasileiro (PROANTAR); e Emitir pareceres e sugestões relativos aos assuntos e atividades relacionadas com os recursos do mar, quando determinado pelo Presidente da República. ${ }^{88}$

A Comissão também tem papel central no Plano de Levantamento da Plataforma Continental Brasileira (Leplac) ${ }^{89}$. É responsavel pela implementação dos Planos Setoriais para os Recursos do Mar (PSRM), que são quadrienais e editados desde 1982. O VIII PSRM, que se encerra em 2015, foi debatido com cientistas e atores não estatais, dentre os seus quatorze objetivos encontram-se o aumento do conhecimento científico, a proteção das Unidades de Conservação marinhas e costeiras e das zonas protegidas marinhas ${ }^{90}$.

Para os recursos sob jurisdição brasileira, há vasta literatura geopolítica sobre a necessidade de defesa armada dessas riquezas, dentre as quais vale destacar o Livro Branco de Defesa Nacional ${ }^{91}$ e a Estratégia Nacional de Defesa ${ }^{92}$. Nas ciências biológicas, encontra-se qualidade mundialmente reconhecida de estudos sobre temas afetos ao mar, porém ainda muito aquém do que o Brasil poderia elaborar. Na pesquisa jurídica e política, curiosamente, o mar foi plutôt preterido ${ }^{93}$. Entretanto, as pesquisas e relatórios oficiais recentes apontam para

88 BRASIL. Ministério do Desenvolvimento, Indústria e Comércio Exterior. Comissão Interministerial para os Recursos do Mar - CIRM (MD). Disponível em: <http://www.mdic.gov.br/sitio/interna/ interna.php?area $=1 \&$ menu $=785 \& \mathrm{refr}=482>$. Acesso em: $22 \mathrm{mar}$. 2015.

89 BRASIL. Ministério da Defesa. O Plano de Levantamento da Plataforma Continental Brasileira: LEPLAC. Disponível em: <https://www. mar.mil.br/dhn/dhn/ass_leplac.html>. Acesso em: 22 mar. 2015.

90 BRASIL. Comissão Interministerial para os Recursos do Mar. Resolução n. 6, de 29 de novembro de 2011. Disponível em: < https:// www.mar.mil.br/secirm/documentos/atas/resolucao-6-2011.pdf>. Acesso em: 22 mar. 2015.

91 Descreve o ambiente estratégico do século XXI com atenção para o Atlântico Sul. BRASIL. Ministério da Defesa. O livro branco de defesa nacional. 2012. Disponível em: < http://www.defesa.gov.br/ arquivos/2012/mes07/end.pdf>. Acesso em: 22 mar. 2015.

92 BRASIL. Ministério da Defesa. Estratégia nacional de defesa. Disponível em: <http://www.defesabr.com/MD/md_estrategia.htm>. Acesso em: 22 mar. 2015.

93 Ver GRANZIEIRA, Maria; GONÇALVES, Alcindo (Org.) Os problemas da zona costeira no Brasil e no mundo. Santos: Unisantos, 2012. Disponível em: <https://www.unisantos.br/edul/public/pdf/zonacosteira.pdf $>$. Acesso em: 22 mar. 2015. a imediata necessidade de integração das instituições, políticas e normas, levando ao conceito de "gestão integrada", tanto da zona costeira com a marinha, como no caso da Amazônia Azul com a Amazonia Legal (ou verde $)^{94}$.

Nesse sentido, a primeira sugestão para a estratégia nacional consiste em abordar a questão marinha de forma mais integrada, considerando os poderes Executivo, Legislativo e Judiciário, mas também os atores subnacionais do mercado e da sociedade, inclusive a local, como destacado acima. Ressalte-se que a estratégia brasileira atualmente encontra-se concentrada no Executivo, o que não facilita a regulação efetiva das questões relativas ao mar em nivel nacional ${ }^{95}$. Em outros termos, o diálogo nacional ainda é fragmentado, por vezes inexistente, tornando a construção do interesse nacional um discurso estranho a atores pertinentes no enfrentamento dos desafios. O consenso sobre os interesses nacionais é primordial, pois como dizem os navegadores, "só há vento favorável para quem sabe onde vai ".

Para os recursos fora de sua jurisdição, é interesse do País investir em tecnologias e pesquisa científica que confortem a sua posição de país emergente e potência ambiental e climática, pois ainda está longe de ser potência marítima. Logo, desenvolver pesquisas na Antártida constitui parte importante da estratégia brasileira. Assim, a segunda sugestão para a estratégia nacional é o fortalecimento de parcerias estratégicas ${ }^{96} \mathrm{com}$ foco específico no mar, o que ainda não existe de forma integrada. França (Guiana Francesa) ao Norte e Uruguai ao Sul são dois interlocutores primordiais com relação ao pleito nacional de extensão da Plataforma Continental, como bem explica Figuerôa ${ }^{97}$.

94 BARROS, Jorge et al. Amazonie bleue et la projection brésilienne sur l'avenir. Revista Outre Terre, Paris, v. 1, n. 42, p. 204-212, 2015. doi: 10.3917/oute1.042.0204.

95 OLIVEIRA, Carina; MONTALVERNE, Tarin; AMARAL JR., Alberto. A implementação no Brasil da obrigação de conservar o meio ambiente marinho: algumas lacunas na preservação da biodiversidade marinha. In: MENEZES, Wagner (Org.). Direito do mar Desafios e Perspectivas. Belo Horizonte: Arraes, 2014. v. 1. p. 250-266. 96 Constitui o ato 3 da Simulação da Estratégia Nacional de Defesa. BRASIL. Ministério da Defesa. Estratégia nacional de defesa. Disponível em: <http://www.defesabr.com/MD/md_estrategia.htm>. Acesso em: 22 mar. 2015. Sobre o conceito e uma análise acadêmica das relações exteriores do Brasil, ver ALTEMANI, H.; LESSA, Antônio Carlos (Org.). Parcerias estrategicas do Brasil: os significados e as experiencias tradicionais. Belo Horizonte: Fino Traço, 2013. v. 1. 97 FIGUEIRÔA, Christiano Sávio Barros. Limites exteriores da plataforma continental do Brasil conforme o direito do mar. Brasília: Fundação Alexandre de Gusmão/MRE, 2014. Disponível em: <http://funag. 
A terceira sugestão constitui a maior participação nacional nos mecanismos multilaterais que constroem a governança dos oceanos. O Brasil precisa participar ativamente dos debates sobre a biodiversidade fora das àreas sob jurisdição nacional, zonas marinhas protegidas, regras de navegação, mineração offshore, combate à pirataria e à biopirataria, dentro e fora das organizações intergovernamentais. Além de participar das agendas de negociação multilateral e bilateral, é importante ratificar os tratados que nos interessam com maior celeridade, e cuidar de sua transposição ao plano interno. $\mathrm{O}$ Brasil ratificou a UNCLOS em dezembro de 1988 (36 Estado), mas a Parte XI apenas em outubro de 2007 (131 ${ }^{\circ}$ Estado). Em março de 2000 ratificou a provisão sobre Populações de Peixes altamente Migratórios $\left(26^{\circ}\right.$ Estado) ${ }^{98}$. Porém, apenas em 2002, o Decreto n. 4631 promulgou o Acordo para Implementação das Disposições da Convenção das Nações Unidas sobre o Direito do Mar de 10 de dezembro de 1982 sobre a Conservação e Ordenamento de Populações de Peixes Transzonais e de Populações de Peixes Altamente Migratórios. Ou seja, foram vinte anos de transposição ao plano nacional, porém isso não significa sua efetiva adoção pelos atores brasileiros, como é o caso atualmente.

Por último, em ordem, mas não em importância, é imprescindível conduzir reforma do arcabouço institucional nacional para que o Brasil administre de facto e de jure seus recursos de forma sustentável, em nome do interesse geral da humanidade e das gerações futuras. Logo, considerando que o Atlântico não constitui obstáculo natural, mas sim uma via de navegação auspiciosa, além de participar mais ativamente de debates multilaterais, a estratégia brasileira deve ser fortalecida no sentido de maior aproximação com seus vizinhos sul-americanos e africanos, como ja é o caso. Globalmente, a estratégia brasileira tomou os rumos corretos, porém ainda carece de reformas institucionais que promovam o diálogo de autoridades nacionais para evitar os entraves burocráticos atuais, a competição interna

gov.br/loja/download/1100-Limites_exteriores_da_plataforma_ continental_do_Brasil_conforme_o_Direito_do_Mar.pdf $>$. Acesso em: 22 mar. 2015.

98 UNITED NATIONS. Division for Ocean Affairs and the Law of The Sea. Chronological lists of ratifications of, accessions and successions to the convention and the related agreements as at 3 October 2014. Jan. 2015. Disponível em: <http://www.un.org/Depts/los/reference_files/chronological_lists_of_ratifications.htm\#Agreement for the implementation of the provisions of the Convention relating to the conservation and management of straddling fish stocks and highly migratory fish stocks >. Acesso em: 21 fev. 2015. por competências regulatórias e o aumento das lacunas no direito e na política.

\section{Considerações finAis: PISTAS dE REFLEXÃo}

Os países emergentes entraram com força na corrida para o mar no momento em que a comunidade científica e política discute sobre a gravidade dos impactos da atividade humana para o Planeta, ou seja, na época do Antropoceno. Constata-se a grande complexidade dos desafios relativos à proteção e à gestão dos recursos marinhos compartilhados, tanto os vivos quanto os não vivos, os quais explicam, mas não justificam, a fragilidade das organizações intergovernamentais multilaterais, a ineficácia do direito internacional público, e a dificil concertação política a nível estatal. Estes são os traços da ordem global ambiental, quando a humanidade coloca em risco a sua própria perenidade por não conseguir criar um arcabouço normativo regulatório para suas atividades no mar. Nesse sentido, a circulação de normas parece uma proposta tanto factível quanto imediata para o avanço dos debates que levem às obrigações positivas dos Estados de proteger e gerir, e dos demais atores por eles representados ou regulados, principalmente os atores do mercado e do setor da tecnologia.

Essa ordem ambiental global interessa particularmente às autoridades brasileiras, ante a megadiversidade nacional, a potencialidade da zona do Pré-Sal, e principalmente pelo potencial que o País tem de se tornar potência econômica no futuro. Para tanto, três pistas de reflexão são propostas. A primeira consiste na integração das instituições nacionais para que haja maior coerência na formulação do interesse nacional. A segunda constitui o fortalecimento de parcerias estratégicas com foco específico no mar, o que ainda não existe. A terceira consiste na maior participação nacional nos mecanismos multilaterais, regionais e bilaterais que constróem a governança dos oceanos. Por último, é imprescindível a reforma institucional nacional para que o Brasil administre concretamente seus recursos de forma sustentável, em nome do interesse geral da humanidade e das gerações futuras, como defendia Alex Kiss. 


\section{REFERÊNCIAS}

ALFAIA JR., José Roberto. Reclamar ou intervir? As obrigações positivas do estado em situações de desastre ambiental. 2014. f. Tese (Doutorado) - Instituto de Relações Internacionais, Universidade de Brasília, Brasília, 2014.

ALTEMANI, H.; LESSA, Antônio Carlos (Org.). Parcerias estrategicas do Brasil: os significados e as experiencias tradicionais. Belo Horizonte: Fino Traço, 2013. v. 1.

BARROS, Jorge et al. Amazonie bleue et la projection brésilienne sur l'avenir. Revista Outre Terre, Paris, v. 1, n. 42, p. 204-212, 2015. doi: 10.3917/oute1.042.0204.

BECARD, Danielly; BARROS-PLATIAU, Ana Flávia; OLIVEIRA, Carina. Brasil, a China e a VI Cúpula do BRICS. Contexto Internacional, v. 37, n. 1, 2015. No prelo.

BEIRÃO, André; PEREIRA, Antonio(Org.). Reflexões sobre a Convenção do Direito do Mar. Brasília: FUNAG, 2014. Disponível em: <http://funag.gov.br/loja/ download/1091-Convencao_do_Direito_do_Mar. pdf>. Acesso em: 22 mar. 2015.

BOULET, Romain; BARROS-PLATIAU, Ana; MAZZEGA, Pierre. 35 years of multilateral environmental agreements ratifications: a network analysis. In: INTERNATIONAL WORKSHOP NETWORK ANALYSIS IN LAW, 2, 2014, Krakow. Anais... Cambridge: Harvard College, 2014. No prelo.

BOURCIER, Danièle; MAZZEGA, Pierre; BOULET, Romain. Visualizer la compléxité du droit. Disponível em: <https://pierremazzega.files.wordpress. com/2010/02/2009bourcieretal-bruylant.pdf $>$. Acesso em: 23 mar. 2015.

BRASIL. Comissão Interministerial para os Recursos do Mar. Resolução n. 6, de 29 de novembro de 2011. Disponível em: <https://www.mar.mil.br/secirm/documentos/ atas/resolucao-6-2011.pdf>. Acesso em: 22 mar. 2015.

BRASIL. Comissão Interministerial para os Recursos do Mar. Seja bem-vindo ao nosso site. Disponível em: <http://www.mar.mil.br/secirm/portugues/principal. html>. Acesso em: 22 mar. 2015.

BRASIL. Ministério da Defesa. Estratégia nacional de defesa. Disponível em: <http://www.defesa.gov.br/arquivos/2012/mes07/lbdn.pdf>. Acesso em: 22 mar. 2015.
BRASIL. Ministério da Defesa. O livro branco de defesa nacional. 2012. Disponível em: <http://www.defesa.gov. br/arquivos/2012/mes07/lbdn.pdf $>$. Acesso em: 22 mar. 2015.

BRASIL. Ministério da Defesa. O Plano de Levantamento da Plataforma Continental Brasileira: LEPLAC. Disponível em: <https://www.mar.mil.br/dhn/dhn/ass_leplac. html>. Acesso em: 22 mar. 2015.

BRASIL. Ministério do Desenvolvimento, Indústria e Comércio Exterior. Comissão Interministerial para os Recursos do Mar - CIRM (MD). Disponível em: <http://www.mdic.gov.br/sitio/interna/interna. php?area $=1 \&$ menu $=785 \&$ refr $=482>$. Acesso em: 22 mar. 2015.

BRASIL. Ministério do Meio Ambiente. Diversidade biológica marinha e costeira: Disponível em: <http://www. mma.gov.br/estruturas/chm/_arquivos/2relat_cap1_ Marinha.pdf>. Acesso em: 22 mar. 2015.

CARLSSON, L.; SANDSTRÖM, A. Network governance of the commons. International Journal of the Commons, v. 2, n. 1, p. 33-54, 2008.

CARVALHO, Fernanda. The Brazilian position on forests and climate change from 1997 to 2012: from veto to proposition. Revista Brasileira de Política Internacional, Rio de Janeiro, v. 55, n. spe, p. 144-169, 2012.

CHINAAFRICA: accueil le magazine du nouveau monde. Paris: SLB, 2015. Disponível: <http://www. chinafrica.info/\#home>. Acesso em: 24 fev. 2015.

CHRISTENSEN, V. et al. A century of fish biomass decline in the ocean. Marine Ecology Progress Series, n. 512, p. 155-166, 9 Oct. 2014.

CHURCH, J.; WHITE, N. Sea-level rise from the late 19th to the early 21 st century. Surveys in Geophysics, v. 32, n. $4 / 5$, p. 585-602, sept. 2011.

CHURCHILL, R. R.; LOWE, A. V. The law of the sea. 3. ed. Manchester: University Press, 1999.

COMISSÃO EUROPÉIA. A política comum das pescas: gestão das pescas na UE. Disponível em: <http:// ec.europa.eu/fisheries/cfp/index_pt.htm>. Acesso em: 22 mar. 2015.

CONFÉRENCE DES PARTIES DE LA CONVENTION-CADRE DES NATIONS UNIES SUR LES CHANGEMENTS CLIMATIQUES, 21, 2015, Paris. 
Procédure eletrônicos... Paris: UNFCC, 2015. Disponível em: <http://www.cop21.gouv.fr/fr>. Acesso em: 23 mar.2015.

CRUTZEN, P. J.; STOERMER, E. F. The anthropocene. Global Change Newsletter, v. 41, p. 17-18, May. 2000.

DAILLIER, Patrick; PELLET. Alain. Droit international public. Paris: LGDJ, 2002.

DELEUIL Thomas. Le statut des pays en voie de développement dans les Accords Multilatéraux Environnementaux. 2014. f. Thèse (PhD) - Centre d'Etudes et de Recherches Internationales et Communautaires (CERIC, CNRS UMR 7318), Faculté de Droit d'Aix en Provence, Université Paul Cézanne Aix-Marseille, Marseille 2014.

DELMAS-MARTY, Mireille. Les forces imaginantes $d u$ droit: le pluralisme ordonné. Paris: Seuil, 2006.

DREZNER, Daniel W. The power and peril of international regime complexity. Perspectives on Politics, v. 7, n. 1, p. 65-70, Mar. 2009.

FIGUEIRÔA, Christiano Sávio Barros et al. O direito dos fundos marinhos internacionais: o patrimônio comum da humanidade 20 após a Convenção de Montego Bay. In: TRINDADE, Antônio Augusto Cançado (Org.). A nova dimensão do direito internacional. Brasília: FUNAG, 2005. p. 29-175.

FIGUEIRÔA, Christiano Sávio Barros. Limites exteriores da plataforma continental do Brasil conforme o direito do mar. Brasilia: Fundação Alexandre de Gusmão/MRE, 2014. Disponível em: <http://funag.gov.br/loja/ download/1100-Limites_exteriores_da_plataforma_ continental_do_Brasil_conforme_o_Direito_do_Mar. pdf $>$. Acesso em: 22 mar. 2015.

FUNTOWICZ, S. O.; RAVETZ, J. R. Science for the post-normal age. Futures, v. 25, n. 7, p. 739-755, Sept. 1993.

GAJA, Giorgio. The protection of general interestsin the international community. Leiden: Brill, 2013. (The Hague Academy collected courses online, 364).

GOIS, Ancelmo; BARROS-PLATIAU, Ana Flávia. Direito internacional e globalização face as questões de direitos humanos. In: RIBEIRO, M.; MAZZUOLI, Valério (Coord.). Direito internacional dos direitos bumanos: estudos em homenagem à professora Flávia Piovesan. Curitiba: Juruá, 2004.
GOLDEMBERG, José; VIOLA, Eduardo. BRICS e as mudanças climáticas. 2014. Disponível em: <http:// politicaexterna.com.br/2580/brics-e-mudancas-climaticas/>. Acesso em: 19 mar. 2015.

GRANZIEIRA, Maria; GONÇALVES, Alcindo (Org.) Os problemas da zona costeira no Brasil e no mundo. Santos: Unisantos, 2012. Disponível em: <https://www.unisantos.br/edul/public/pdf/zonacosteira.pdf $>$. Acesso em: 22 mar. 2015.

GRANZIERA, Maria Luiza; GONÇALVES, Alcindo. Os problemas da zona costeira no Brasil e no mundo. São Paulo: Universitária Leopoldianum, 2012.

HASSAN, Rashid; SCHOLES, Robert; ASH, Neville. Ecosystems and human well-being: current state and trends: findings of the Condition and Trends Working Group. Washington: Millennium Ecosystem Assessment, 2005. (The Millennium Ecosystem Assessment Series; v. 1). Disponível em: <http://www.millenniumassessment. org/en/Condition.html>. Acesso em: 27 mar. 2015.

HEAD, B. W.; ALFORD, J. Wicked problems: implications for public policy and management. Administration and Society, v. 20, n. 10, p. 1-29, Mar. 2013. Disponível em: <http://aas.sagepub.com/content/ear ly/2013/03/27/0095399713481601.full.pdf $>$. Acesso em: 22 mar. 2015.

HURRELL, Andrew. On global order: power, values, and the constitution of international society. Oxford: Oxford University Press, 2007.

IKENBERRY, John. The future of the liberal world order. internationalism after america. Foreign Affairs, New York, v. 90, n. 3, p. 56-68, May/June, 2011.

INOUE, Cristina. Projetos de cooperação internacional, comunidades epistêmicas e conceito de regime global de biodiversidade: o caso de Mamirauá. In: CARVALHO, Maria Izabel; SANTOS, Maria Helena (Org.). O século 21 no Brasil e no mundo. São Paulo: Edusc, 2006.

INTERGOVERNMENTAL PANEL ON CLIMATE CHANGE. Chapter Climate Change 2014: synthesis report, summary for policymakers. Disponível em: <http://www.ipcc.ch/pdf/assessment-report/ar5/ syr/AR5_SYR_FINAL_SPM.pdf $>$. Acesso em: 22 mar. 2015.

INTERGOVERNMENTAL platform on biodiversity and ecosystem services. 2015. Disponível em: < http:/ / www.ipbes.net/>. Acesso em: 23 mar.2015. 
KEOHANE, Robert O.; VICTOR, David G. The regime complex for climate change. Perspectives on Politics, v. 9, n. 1, p. 7-23, 2011. Disponível em: < http://ilar. ucsd.edu/assets/001/501988.pdf >. Acesso em: 22 mar. 2015.

KISS, Alexandre. Droit international de l'environnement. Paris: A. Pedone, 1989.

KØRNØV, L.; THISSEN, W. A. H. Rationality in decision and policy-making: implications for strategic environmental assessment. Impact Assessment and Project Appraisal, v. 18, n. 3, p. 191-200, 2010.

KOSKENNIEM, Martti. Fragmentation of international law: difficulties arising from the diversification and expansion of international: report of the study group of the international law commission. 13 Apr. 2006. Disponível em: <http://legal.un.org/ilc/documentation/ english/a_cn4_1682.pdf>. Acesso em: 27 mar. 2015.

MALJEAN-DUBOIS, Sandrine. La mise en couvre du droit international de l'environnement. Paris: IDDRI, 2003. (les Notes de L'iddri, n. 4) Disponível em: < http://www. peacepalacelibrary.nl/ebooks/files/337934460.pdf $>$. Acesso em: 27 mar. 2015.

MARQUES, Fabrício. Corrida sobre o gelo. Disponível em: <http://www.revistapesquisa.fapesp.br/wp-content/ uploads/2012/04/032-037_1941.pdf?f0d91f>. Acesso em: 25 mar. 2015.

MASLIN, Mark A. Defining the anthropocene. Nature News, n. 519, p. 171-180, 12 Mar. 2015.

MICHAEL, J. et al. Navigating the maritime piracy regime complex. Global Governance: a review of multilateralism and international organizations, v. 19, n. 1, p. 93-104, Jan./Mar., 2013.

MOLTZ, James Clay. Submarine and autonomous vessel proliferation: implications for future strategic stability at sea. Disponível em: <http://calhoun.nps.edu/ handle/10945/34355 em 2012>. Acesso em: 23 mar. 2015.

MONASTERSKY, Richard. Anthropocene: the human age. Nature, n. 519, p. 144-147, 12 March 2015. Disponível em: <http://www.nature.com/news/anthropocene-the-human-age-1.17085>. Acesso em: 22 mar. 2015.

MORIN, Jean-Frédéric; ORSINI, Amandine. Essential concepts of global environmental governance. Abingdon: Routledge, 2014.
NOBRE, Antônio. O futuro climático da Amaẑônia: relatório de avaliação científica. São José dos Campos: ARA, 2014. Disponível em: <http://www.ccst.inpe.br/ wp-content/uploads/2014/10/Futuro-Climatico-daAmazonia.pdf> . Acesso em: 22 mar. 2015.

NYE, Joseph. Understanding 21st century power shifts. Disponível em: <http://www.europeanfinancialreview. com/?p=2743.June 24, 2011 > . Acesso em: 21 fev. 2015.

OLIVEIRA, C. C. Critérios jurídicos para a responsabilidade civil decorrente de bioinvasão: o caso do coralsol. A Ressurgência, Niterói, v. 7, p. 21-22, 2013.

OLIVEIRA, Carina; MONTALVERNE, Tarin; AMARAL JR., Alberto. A implementação no Brasil da obrigação de conservar o meio ambiente marinho: algumas lacunas na preservação da biodiversidade marinha. In: MENEZES, Wagner (Org.). Direito do mar: desafios e perspectivas. Belo Horizonte: Arraes, 2014. v. 1. p. 250266.

OLIVEIRA, Liziane. A convenção sobre diversidade biológica e o princípio de soberania nacional, 2006. 176 f. Dissertação (Mestrado em Direito) - Faculdade de Direito, Universidadede Brasilia, Brasilia, 2006.

ORSINI, Amandine; MORIN, Jean- Frédéric; YOUNG, Oran. Regime complexes: a buzz, a boom, or a boost for global governance? Global Governance, v. 19, n. 1, p. 27-39, Jan./Mar. 2013.

OSTROM, Elinor. Coping with the tragedy of the commons. Annual Review of Political Science, v. 2, p. 493-535, June 1999.

OSTROM, Elinor. Governing the commons: the evolution of institutions for collective action. Cambridge: Cambridge University Press, 1990.

PITT, J.; SCHAUMEIER, J.; ARTIKIS A. The axiomatisation of socio-economic principles for self-organising systems. ACM Transactions on Autonomous and Adaptive Systems, v. 7, n. 4, p. 1-39, Dec. 2012. Disponível em: <http://dx.doi.org/10.1145/2382570.2382575>. Acesso em: 22 mar. 2015.

PRANTL, Jochen. Taming hegemony: informal institutions and the challenge to western liberal order. The Chinese Journal of International Politics, Oxford, v. 7, n. 4, p. 449-482, Winter, 2014.

PROST, Mario. Unitas multiplex: unites et fragmentations en droit international. Bruxelles: Bruylant, 2013. 
PROST, Mario; TORRES, Camprubi. Against fairness? International environmental law, disciplinary bias and pareto justice. Leiden Journal of International Law, v. 25, n. 2, p. 379-396, 2012.

RAUSTIALA, Kal; VICTOR, David G. The regime complex for plant genetic resources. International Organization, v. 58, p. 277-309, Spring 2004.

RAYFUSE, R.; WARNER, R. M. Securing a sustainable future for the oceans beyond national jurisdiction: the legal basis for an integrated cross-sectoral regime for high seas governance for the 21 st century. International Journal of Marine and Coastal Law, v. 23, n. 3, p. 399-421, 2008.

REMOND-GOUILLOUD, M. Du droit de détruire. Paris: Universitaires de France, 1989.

RIBEIRO, Wagner. Ordem ambiental internacional. São Paulo: Contexto, 2001.

SAMPAIO, Daniela. Antarctica and international cooperative practices. São Paulo: International Studies Association, March 2014. (working paper). Disponível em: < http:// www.academia.edu/10185759/Antarctica_and_International_Cooperative_Practices_working_paper>. Acesso em: 23 mar. 2015.

SASSEN, Saskia. Losing control? Sovereignty in the age of globalization. New York: Columbia University Press, 2015.

SCOVAZZI, Tullio. Direito internacional público. Haia: Academia de Direito da Haia, 2000. p. 232.

SCOVAZZI, Tullio. Marine protected areas on the high seas: some legal and policy considerations. The International Journal of Marine and Coastal Law. v. 19, n. 1, p. 01-17, 2004.

SHEPHERD, N. G.; MAYNARD, R. The influence of context on the strategic decision-making process: a review of the literature. International Journal of Management Reviews, v. 16, n. 3, 2014, p. 340-364, 2014.

SIIRILÄ, Erkki. UN atlas: 44 percent of us live in coastal areas. Jan. 2010. Disponível em: <http://coastalchallenges.com/2010/01/31/un-atlas-60-of-us-live-inthe-coastal-areas/>. Acesso em: 23 mar. 2015.

SOUZA, Rosa Cristina de. Água de lastro: uma ameaça à biodiversidade. In: REUNIÃO ANUAL DA SBPC, 62, 2010, Natal. Ciências do mar: herança para o futuro, Anais... Natal: SBPC, 2010. Disponível em: <http:// www.sbpcnet.org.br/livro/62ra/mesas_redondas/ MR\%20Rosa \%20Cristina \%20Corr\%C3\%AAa \%20 Luz\%20de\%20Souza.pdf>. Acesso em: 02 abr. 2015.

UNITED NATIONS. Division for Ocean Affairs and the Law of The Sea. Chronological lists of ratifications of, accessions and successions to the convention and the related agreements as at 3 October 2014. Jan. 2015. Disponível em: $<$ http://www.un.org/Depts/los/reference_files/chronological_lists_of_ratifications.htm\#Agreement for the implementation of the provisions of the Convention relating to the conservation and management of straddling fish stocks and highly migratory fish stocks $>$. Acesso em: 21 fev. 2015.

UNITED NATIONS. Department of Economic and Social Affairs. Goal 14: conserve and sustainably use the oceans, seas and marine resources for sustainable development. Disponível em: <http://una-gp.org/clancyt/ files/goals/goal14.pdf>. Acesso em: 23 mar. 2015.

UNITED NATIONS. Oceans and the law of the sea: letter dated 25 July 2014 from the Co-Chairs of the Ad Hoc Open-ended Informal Working Group to the President of the General Assembly. Disponível em: <http:// www.un.org/depts/los/biodiversityworkinggroup/documents/BBNJreport_69_177.pdf>. Acesso em: 22 mar. 2015.

UNITED NATIONS. Resolution adopted by the General Assembly, 4 of February of 2005: Oceans and the law of the sea. Disponível em: <http://www.unga-regularprocess.org/images/Documents/un\%20a-res-59-24. pdf>. Acesso em: 22 mar. 2015.

VARELLA, Marcelo. Internationalization of law: globalization, international law and complexity. Brasília: Centro Universitário de Brasília, 2013.

VIDAS, Davor; SCHEI, Peter Johan. The world ocean in globalization: challenges and responses for the anthropocene epoch. Leiden: Martinus Nihhoff Publishers, 2011.

VIOLA, Eduardo; FRANCHINI, Matías; RIBEIRO, Thaís. Sistema internacional de hegemonia conservadora: democracia e governança global na era da crise climática. São Paulo: Annablume, 2013.

WELCOME to the Anthropocene. The Economist, May, 2011. Disponível em: <http://www.economist.com/ node/18744401>. Acesso em: 23 mar. 2015.

YANG, T.; PERCIVAL, R. V. The emergence of global 
environmental law. 2009. Disponível em: < http://digitalcommons.law.scu.edu/cgi/viewcontent.cgi?articl $\mathrm{e}=1714 \&$ context $=$ facpubs, ou http://ssrn.com/abstract $=1269157>$. Acesso em: 21 fev. 2015.
ZIELINSKI, Sarah. Ocean dead zones are getting worse globally due to climate change. Disponível em: <http://www. smithsonianmag.com/science-nature/ocean-deadzones-are-getting-worse-globally-due-climate-change180953282/?no-ist>. Acesso em: 21 mar. 2015. 
Para publicar na Revista de Direito Internacional, acesse o endereço eletrônico www.rdi.uniceub.br ou www.brazilianjournal.org.

Observe as normas de publicação, para facilitar e agilizar o trabalho de edição. 